\title{
THE THEORY AND PRACTICE OF
}
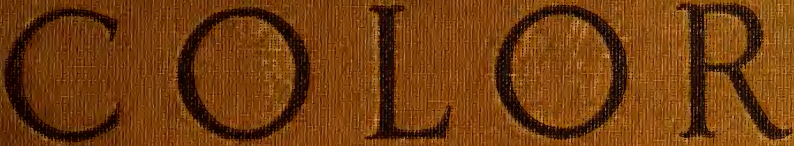

\section{BONNIE E. SNOW HUGO B. FROEHLICH}




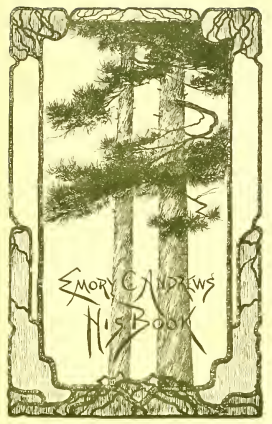

Cooper-Hewitt Museum Library

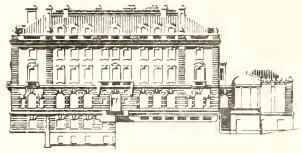

Gift of

WALTER C GRANVILLE

Smithsonian Institution Libraries 






\section{THE THEORY AND PRACTICE OF COLOR}






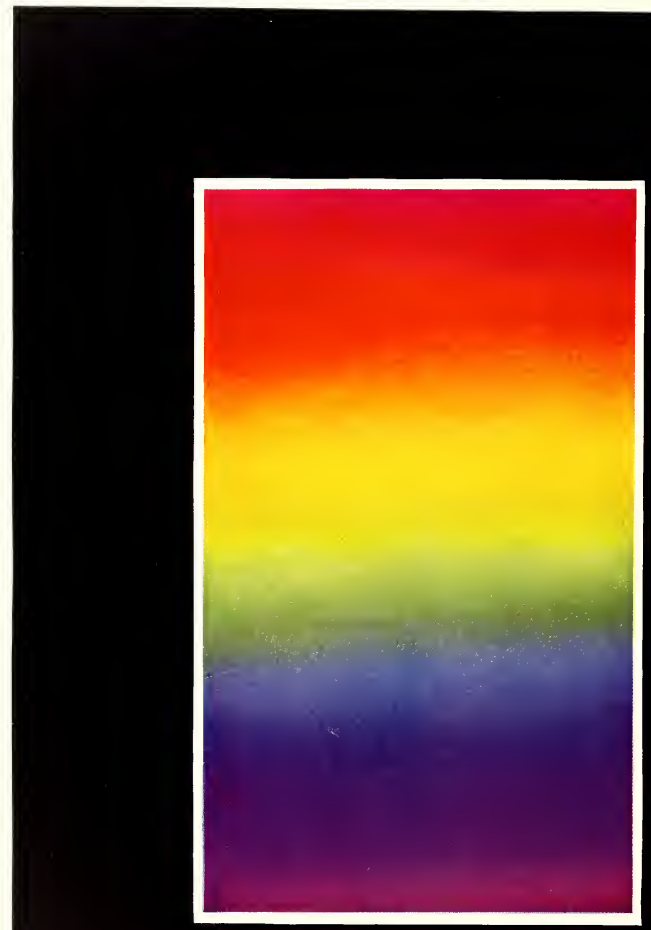

A Symbol of the Rainbow 


\section{THE THEORY AND PRACTICE OF}
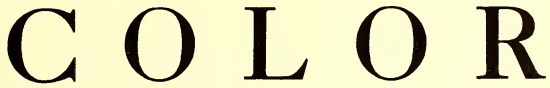

By

BONNIE E. SNOW

HUGO B. FROEHLICH

THE PRANG COMPANY NEW YORK CHICAGO 


\section{Copyright, 1918}

By Bonnie E. Snow and Hugo B. Froehlich
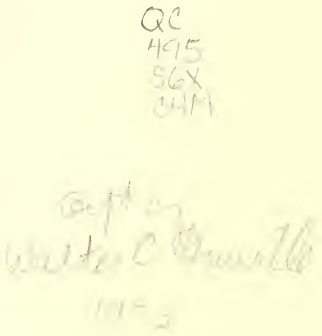


\section{THE PREFACE}

$\mathbf{U}$

$\mathrm{P}$ to the present time, the study of Color has been approached from three different angles: the angle of the physicist, the angle of the chemist and the angle of the painter or artist. The physicist has demonstrated that the sun is the source of all Color, and has unlocked for us the secrets of the Solar Spectrum. The chemist has found in certain clays, in plant and animal life and in bi-products of coal, various symbols and substitutes for Color which he calls pigment, and which he combines in wonderful ways to make our dyes, paints and inks. The artist-painter has made use of the chemist's formulae in the instrument which he uses to portray his interpretation of nature, his marvelous flights of imagination and the depth of his insight into the human heart. But all three of these workers, indispensable as each one is to the growth and development of the world, have ignored the individual man and his needs.

Though living in a world of Color, and forced by the nature of all created things to the daily and hourly use of Color, the average man is densely ignorant of any laws or principles which will guide him in its intelligent use. He has been sailing in uncharted seas, and, as a result, he has often found himself upon the rocks of discordant and irritating Color combinations, in his home, in his dress and in his efforts to meet the demands of business advertising.

Moreover, the enjoyment of Color, in itself as pure and exquisite a pleasure as the enjoyment of music, has been for him a sensation unknown. He has believed that Color belongs to a mysterious realm, inhabited only by artists, geniuses and others who are "born to the purple." He has been told that the appreciation of Color is a matter of feeling and emotion, and that if he does not nsturally "thrill" to chords of Color struck by a master hand, then there is no way for him to acquire the ability to enjoy Color and to understand its use, except through years of practice in the technical processes of so-called Art training.

This book, with its Color Charts, is compiled for the purpose of discovering to the ordinary man the World of Color. The Charts are the keys that unlock a vast storehouse. The Charts, purely scientific as they are, will cause the doors of the storehouse to swing wide. All who 
will, may enter and carry away the priceless gems. Familiarity with this scientific basis of Color can never restrict the play of man's emotions, nor deaden his vibrations. Indeed, the more he knows about Color, the greater is his pleasure in using it.

That the simple Theory herein expounded may be of service to students of all ages, who wish to know that they may more fully live, is the sincere desire of the authors.

Grateful acknowledgment is made to Mr. Frank Alvah Parsons, President of the New York School of Fine and Applied Arts, whose presentation of this Color Theory as fundamental in all Art training first attracted the attention of the authors and suggested to them the simplified series of Charts which appears in this book. 


\section{TABLE OF CONTENTS}

The Preface . . . . . . . . . . . . . . 5

Chapter I A World of Color . . . . . . . 9

Chapter II The Source of Color . . . . . . . 13

Chapter III The Primary Colors and Their Uses in Design . 15

Chapter IV The Binary Colors and How to Use Them . . 17

Chapter V Color Values: Tints and Shades . . . . 19

Chapter VI Complementary Colors and How to Use Them . 22

Chapter VII Neighboring or Analogous Colors . . . . 25

Chapter VIII The Color Triad and the Split Complement. . 28

Chapter IX Color in Various Degrees of Intensity-or Grayed Colors . . . . . . . . 31

Chapter X The Psychology of Color . . . . . . 33

Chapter XI Color Harmonies in Costume . . . . . 38

Chapter XII Color Harmonies in Interior Decorations . . 42

Chapter XIII Color in Commercial Design . . . . . 47 


\section{COLOR CHARTS AND DIAGRAMS}

Facing Page

Frontispiece-A Symbol of the Rainbow $\ldots \ldots \ldots \ldots \ldots \ldots \ldots . . \ldots$

Value Chart of Neutral Gray and Two Colors (Hand Painted) ..... 9

Figure I-A device for Locating Complementary Colors........ 24

Figure II-A device for Locating a Triad of Colors.......... 28

Figure III-A device for Locating a Split Complement........ 30

Chart I-Primary Colors (Hand Painted) .............. 16

Chart II-Binary Colors (Hand Painted) $\ldots \ldots \ldots \ldots \ldots \ldots \ldots$

Chart III-Normal Colors and Tints (Hand Painted) .......... 20

Chart IV-Normal Colors, Tints and Shades (Hand Painted) .... 22

Chart V-Complementary and Neutral Gray (Hand Painted) ... 24

Chart VI-Primary Colors, Binary Colors, Hues and Analogous Color Schemes (Hand Painted) .............. 26

Chart VII-Colors in Full Intensity and Grayed Colors (Hand Painted ) ............................. 32

Chart VIII-Colors in One-Half and One-Fourth Intensities. Monochromatic Color Schemes. Analogous Color Schemes. Complementary Color Schemes. (Hand Painted ) ............................ 36 


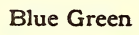

H L

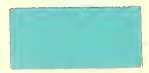

L

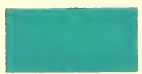

L L

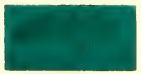

M

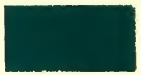

H D

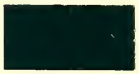

D

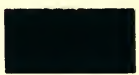

L D
White
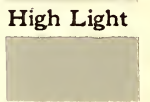

Light

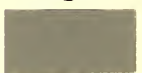

Low Light

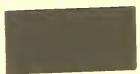

Middle

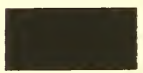

High Dark

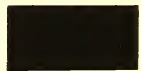

Dark

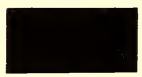

Low Dark

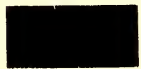

Black
Red Orange

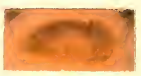

H L

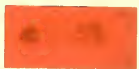

L

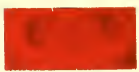

L L

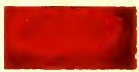

M

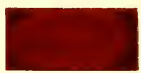

H D

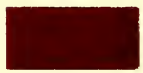

D

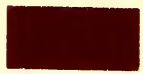

L D

VALUE SCALE IN TWO COLORS AND NEUTRAL TONES 


\section{THE \\ THEORY AND PRACTICE \\ OF COLOR}

Chapter I

\section{A WORLD OF COLOR}

$\mathbf{I}^{N}$

$\mathrm{N}$ this world we are surrounded by Color. Every object that we see, of any kind, in any place, has Color. It is the one great distinguishing factor which enables us to separate in our vision one object from another. When the darkness of night descends upon our world and the light of the moon and the stars is obscured by storm clouds, we grope about blindly. We cannot see objects which we know are in the old familiar places, because their Color is hidden from us by the dark.

We look from the window, and we see a kaleidoscopic array of color shapes. There are people on the streets; trees and buildings rising against the sky; patches of blue above the clouds; ascending columns of smoke and steam; there are housetops and chimneys; waving flags and banners; street cars, automobiles, sign boards and shop windows; all, all are playing their part in the great color orchestration.

We look about the room in which we sit. Every object and element in it possesses the quality of color. The floor, if of wood, is perhaps a tone of gray orange, which we commonly call brown. The "trim" of the room may be chestnut, or polished mahogany or painted pine. Whatever its finish or tone, it has Color. The walls are of rough plaster, or they are calcimined or papered. They, too, possess the inevitable quality of Color. The curtains, the window shades, even the glass of the panes have Color. The rugs and hangings we have long been accustomed to think of as Color notes, but they possess Color no more, though of different quality, than do the structural elements of the room. If in our room all of these color elements are combined intelligently, the effect is 
harmonious and restful. If they are used thoughtlessly or in ignorance, we are unsatisfied, and we wonder why some rooms are so much more beautiful than others. Beauty is never the result of mere outlay or expense. It depends on knowledge of the laws of Color, either intuitive, or consciously acquired.

So fundamental is the element of Color that we cannot escape its use, even if we would. No part of the costume of a human being can be separated from Color. The hat, the coat, the shoes of the laborer are as full of Color as the millinery, the velvet and the costly furs of the lady of wealth. But the peasant may be as beautiful in his costume, as the prince is in his, if only his colors sing in tune, and the lines of his costume are in structural harmony with his figure.

Since in this, our world, we are compelled to see Color, to use Color, and to live Color, why should we not extract the fullest enjoyment from Color? Our bodies are nourished by food. We expend much time and money in the effort to make that food palatable. Color feeds the senses, the emotions and that all important and all controlling factor of our being, the spirit. Why, then, shall we not feast our eyes on the beauty of color in its endless phases of delight, as we have learned to feast our ears upon that harmony of sounds which we call music?

Color is a language through which man expresses his thoughts and ideas, his feelings and aspirations. We say that a painter expresses himself on canvas; that he "interprets" Nature to us, or shows us through the use of his pigments his moods, his spiritual insight into character and his visions. But it rarely occurs to us that we also express ourselves through Color. Our houses, our clothes, our offices, our shops and factories, our streets and gardens, our schoolrooms, our surroundings and perquisites everywhere proclaim us. We cannot prevent this inevitable advertisement. What we choose and buy and wear and use tells with brutal frankness what we are.

Since Color is so universal a language which we cannot choose but speak, it behooves us to speak it beautifully. The educated American is known by the quality of his "English." Our ears are trained to detect grammatical errors. If a person is guilty of such a lapse as "Between you and I," or "He done well" he is instantly classified as ignorant of the usage of correct speech. But thousands of people, otherwise educated, 
commit just as glaring errors in the grammar of Color; for there are laws which govern the various combinations and relationships of Color, just as there are laws that govern the combinations and relationships of words. In our former teaching, we were accustomed to think of Color relationships as being governed by feeling, or taste, or some other heaven-sent intuition. But now we know that color relationships can be taught, as definitely as we teach the rules of grammar. Those gifted with a Color sense will still possess advantage over the average individual, but in the light of Color knowledge, the average individual can be kept from creating and tolerating discords, and through instruction can become a living example of Color harmonies.

In man's more intimate life, as well as in his business environment, the relationships of Color play no mean part in influencing his nature. Consciously or unconsciously he is affected by his surroundings. That mysterious quality which we call "atmosphere" is very largely a question of Color adjustments, and it is a matter of immense importance whether the atmosphere with which one is surrounded is discordant and jarring or serene and restful.

The civilization in which we find ourselves today is ceaselessly opening new fields of activities in industry, in commerce and in education where a thorough training of the color sense and a knowledge of Color in its various relationships are positively essential.

In the future, America must manufacture from the raw products her own dyestuffs, paints and pigments. Her industrial workers, her chemists, her manufacturers, her lithographers, printers and colorists of every kind and calling must be trained in the understanding and the use of Color. Already, under the pressure of these times, the American chemist has risen to the need of the hour and has produced a range of commercial Colors, in dyes, inks and various pigments which will forever establish his ability to solve for his country the problems of Color manufacture. These are considerations quite apart from the training of the aesthetic sense, in all individuals. The aim and desire for a higher standard of life, industrially, commercially, educationally and spiritually cannot be realized without a knowledge of that subtle medium, Color, with which we are always and everywhere surrounded.

In the effort to place the teaching of Color upon a scientific and ped- 
agogical basis, the simplest and most easily used theory has been adopted, in this book. So far as individual students of mature minds and judgment are concerned it seems to be a matter of small importance whether the Brewster theory, the Rood theory, the Munsell theory, the Ross theory, or any other theory is used, in the effort to clarify, systemize and make definite one's ideas of Color. The essential thing is that the worker adopts a theory that it is to him workable and satisfactory. It is necessary for the worker to think about Color intellectually, as well as to feel it emotionally; to be able to give reasons for the use of his combinations of Color. He should arrive at a thoughtful appreciation of Color harmony, as well as at an esthetic enjoyment of Color. In the case of the average human being, not gifted with a special Color sense, it is imperative that he be given a Chart to sail by, rather than to be left to the accident of choices which he is compelled to make from the vast ocean of Color in which he finds himself. We should acknowledge that there is a science of Color, just as there is a science of Music. While in Color the cultivated eye must be the final test, as the cultivated ear is the final test in Music, still the results obtained should not violate well defined Color principles, and these principles should be so simply presented that everybody can understand and use them.

Belief in a Color theory and the use of a Color Chart are means and aids to the attainment of beauty. When American industry appreciates the commercial value of beauty in the manufactured product, our country will stand a chance of winning commercial supremacy in the markets of the world. 


\section{Chapter II}

\section{THE SOURCE OF COLOR}

T $\mathrm{N}$ physics we analyze a ray of light; we separate it into its component parts; we discover laws of transmission, refraction, reflection; we determine the wave lengths of different Colors and the effects of different Colors upon the retina of the eye. Such study is purely physical, and has to do with the wonderful properties of Light, the source of all Color. The results of such study are of great scientific value, but they contribute very little to the cultivation of the Color sense. The physicist's aims are purely scientific. He tells us that a ray of sunlight separated by means of a spectroscope into its component parts, shows red, green and blue-purple as the three elements which in various combinations produce all other colors. But the artist, the designer, the maker of dye stuffs and other coloring matter cannot make use of these physical elements of Color. The artist, the designer, the decorator, the printer, the dyer, the house painter, the teacher, the pupil, the citizen is dependent for Color expression not on rays of light but upon pigments. Pigments are symbols of Color. They are Color representations, and their combinations produce results that differ in many particulars from the combinations of different rays of Colors secured from Light.

Pigment is obtained from various sources. As in the days of the Egyptians, we must still go to Mother Earth for our most important and permanent Colors, such as yellow uchre, raw sienna, the umbers, vandyke brown, cobalt, ultra-marine, cadmium and white. From the animal kingdom we derive our carmine, crimson lake, purple lake, indian purple, sepia and other colors. Vegetables and plants are the sources of gamboge, indigo, and the family of madders. In the early days the master dyer and painter made his own colors, and he worked with a limited palette. He himself ground, or his apprentice did, all the colors that he required. In fact, apprenticeship began with color grinding. Gradually the palette of the painter was increased by the addition of other pigments, discovered by various masters. In time the manufacture of colors 
became a specialized occupation, a distinct profession, until today we find it a vast Color industry, of immense commercial importance.

The physicist, as we have said, in his investigations goes to the source of all Color, the white light of the sun. He finds that a ray of white light when passed through a glass prism and thrown upon a wall or screen, produces a band of Color like a rainbow. $\mathrm{He}$ calls this band the spectrum. These spectrum colors he uses in all his experiments and deductions. He is not concerned if combinations of pigments do not bear out the truths that he discovers in dealing with the spectrum Colors themselves. The artist and the industrial worker, however, must deal with pigments and with those principles and formulae that concern them. It does not matter to the makers of dyes if, as the physicist says, red light and green light in mixture produces yellow light, when they find by experiment that red pigment and green pigment in mixture produce gray. No matter what the spectroscope may demonstrate regarding the combination of yellow rays of light and blue rays of light, the fact remains that yellow pigment mixed with blue pigment produces green pigment. Similarly regardless of the spectroscope, blue pigment mixed with red pigment produces violet pigment.

Shall we teach a false color theory? By no means! Let us teach a theory that can be proved through the use of pigments in the Color world in which we live. Let us seek for a clearer understanding of the truth, and harmonize our teaching with the truth. With our Color theories and our Color Charts we wish to lead the people to an appreciation of fine Color. Our public schools should be responsible for teaching a certain amount of definite Color knowledge and this knowledge should influence the people in the choices they will inevitably make of Colors in costumes, house-furnishings and in commercial commodities. It will be useful for the common people to know that certain combinations of Color can be depended upon to produce beauty and that other combinations should be avoided, because they result in discord. The so-called Red, Yellow and Blue theory seems the simplest, the most widely used and understood, and the most practical for educational and general purposes that has yet been devised. In the explanations and demonstrations which follow, let it be borne in mind that pigments are the media employed and that it is the intelligent use of pigments in their manifold forms that will best develop Color appreciation. 


\section{Chapter III}

\section{THE PRIMARY COLORS AND THEIR USE IN DESIGN}

HE prismatic band, or spectrum, has been symbolized by a beautiful rhythm of painted colors, beginning with red, and passing through successive steps of orange, yellow, green and blue to red-violet. (See frontispiece). In the rainbow or prismatic group itself some of these Color tones are missing.

Among these is the pure, typical red, which leans neither to orange nor to violet. In the color charts in this volume we have represented the Colors of the spectrum and also the missing steps in the complete circuit of Color tones. In dealing thus with pigments we find that there are three Colors which are the basis for all other colors, and that these three are yellow, red and blue. These Colors are in themselves elements and cannot be produced by mixture. Therefore we call them Primary Colors.

In studying the relationships of the different tones in our scale of Colors, it has been found convenient to arrange them in a circle, the first elements of which are shown in Chart I. Here the three pigment primaries, yellow, red and blue, appear in their greatest strength or intensity. They are therefore called normal yellow, normal red, normal blue, because they are unmodified and undiluted.

The three Primary Colors in their full intensity, differing so widely in their tone and quality, are instantly recognized by little children who start with them as the first steps in the acquirement of definite Color knowledge. Many interesting exercises may be planned to vitalize and make practical the purely scientific facts presented. Children are trained to avoid the use of two primaries (as red and yellow, red and blue, blue and yellow) in any exercise or arrangement involving the decorative use of Color.

They are taught to combine any one of the Primaries in its full intensity with a neutral-that is, with black or white or gray, or with a combination of all or any two of these neutral tones. In the first problems of elementary design, the children may print with sticks, making 
many border designs and surface patterns by the repetition of some simple geometric shape, printed in yellow, red or blue, or white or light gray paper. If opaque Colors are available, shapes of white or yellow may be printed upon black paper. Cut paper shades of black, white or gray may be pasted upon yellow, red or blue backgrounds, or the order may be reversed, and the bright shapes of paper may be arranged upon backgrounds of the neutral tones. Black and white checked ginghams may be printed with shapes of a Primary Color, and these interesting patterns made up into bags, holders and other useful articles. The costumes of paper dolls may show combinations of a neutral with a Primary,-a blue dress may be trimmed with white, a gray coat with red, or a black cap with red or yellow. With children who are beginning this definite study of Color, it is well to limit the decorative use of Color to the group presented in the Chart at a particular stage, for only by working within limitations will invention be stimulated. Thus will our courageous and intelligent use of Color begin. We shall not hesitate to use bright Color when we know what combinations to make and how to balance intense tones of color by judicious combination with neutrality. 


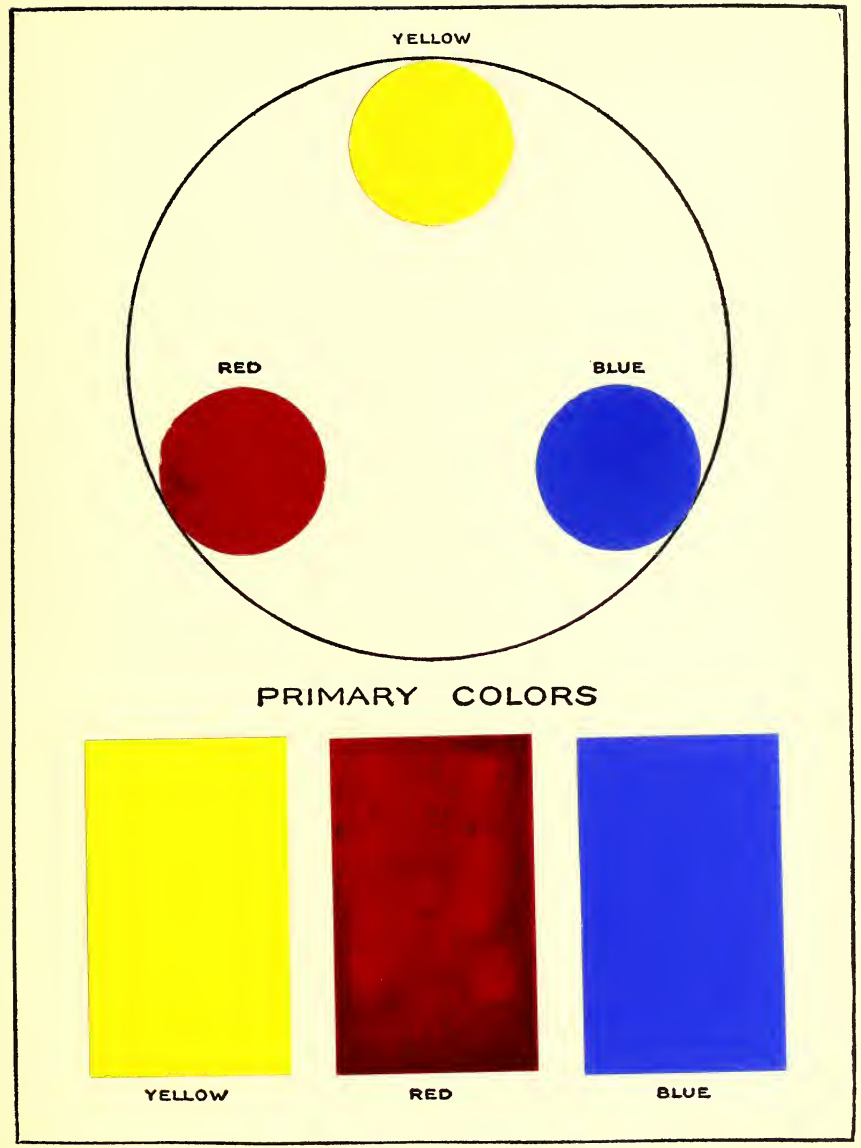

CHART ONE 



\section{Chapter IV}

\section{THE BINARY COLORS AND HOW TO USE THEM}

TF we start with the three Primary pigments, yellow, red and blue as a basis, we have a foundation for all other color tones that can be pro1 duced by mixture. The simplest ratio of combination is to mix equal parts of any two primaries, producing in this way, by each mixture, a third color, which we call a binary Color. There are three Binary Colors, orange, green and violet, which are produced as follows: Equal parts of yellow and red in mixture, produce the Binary orange; equal parts of yellow and blue, in mixture, produce the Binary green; and equal parts of red and blue, in mixture, produce the Binary violet.

Chart No. II shows the Binary Colors orange, green and violet placed so that each Binary is seen between its two constituent Primary Colors.

An interesting way of demonstrating these scientific facts of Color mixtures, especially before a class, is to prepare beforehand solutions of the Primary Colors in comparatively large quantities, mixing them in pairs as follows: dissolve in each of three glasses of water two hard cakes of Water Color,-yellow in one glass, red in another and blue in the third. These cakes should soak over night. In the morning stir each fluid with a clean spoon or stick. The solutions will then be ready for use. They will appear in the glasses at their normal tones, or in full intensity, as we say. In a fourth glass, pour about a quarter of the solution of yellow, and the same amount of red solution. The results will be orange. In a fifth glass pour equal amounts of yellow and blue. The result will be green. In a sixth glass pour equal amounts of red and blue. The result will be violet.

Beginners of all ages will find the mixing and spreading of these Color tones a great aid to the understanding of Colors and their relationships. Even children in primary grades can be taught to mix and spread all of the Color washes that are presented in Charts I, II, and III. The duplication of these Charts is strongly recommended. In no 
other way can Color experience be so definitely gained. Even if the Color standards shown in the Charts are not reached, the effort to "measure up" to them is of great value. Water Colors, either transparent or opaque, are the best mediums for chart making. Where the mixing of Colors is not practicable, colored papers may be employed for the teaching of the theory of Color; but color experience can only be gained through the actual processes of mixing and spreading the various Color tones in the charts. The simpler and more easily recognized tones are found in the first five Charts. After that, the new Colors presented are more subtle and therefore more difficult to mix.

In decorative design the Binary mixtures open up to us a rich field of Color. Any Color with two component parts is more interesting than a purely elemental or Primary Color. For instance, orange is a color of greater decorative value than either yellow or red; green has more "quality" than either blue or yellow; and violet is distinctly more interesting than either red or blue.

The Binary colors, like the Primaries, can be effectively combined with any or all of the neutral tones, white, black or gray. In schools where Color is taught definitely, the decorative use of Color in the second grade is confined to the Primaries and the Binaries, in their normal tones, combined with one or more neutrals. Combinations of the Binaries should not at this time be permitted, nor combinations of a Primary and a Binary. When at a later stage of the development of Color study the idea of Complementary Colors and the theory of complementary harmonies are presented, combinations of Primaries and Binaries may be made. But as everything depends for Color harmony upon how these Colors are used, it is best to limit Color combinations, in elementary problems, to the use of any one of the six Colors already presented with one or more neutral tones. 


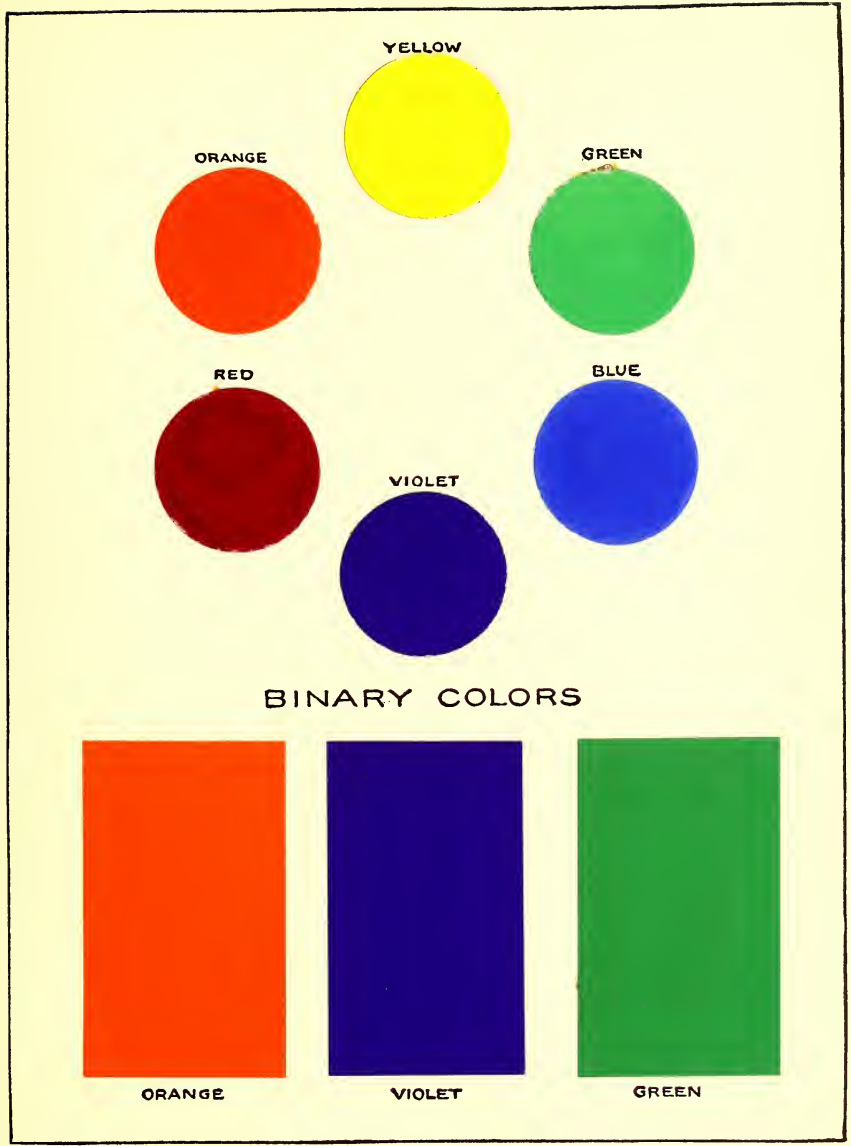

CHART TWO 


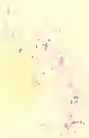




\section{Chapter V}

\section{COLOR VALUES: TINTS AND SHADES}

$\mathrm{O}$ $\mathrm{NE}$ of the advantages of a definite knowledge of Color, gained through the study and analysis of Color Charts, is the ability to classify and name all the different Color tones that we see about us, in flowers, in the landscape, in materials of all kinds, and in dyes, paints, inks and other forms of pigment. To give each Color tone its place and name, we must understand the various properties or qualities of Color. In the study of grammar we first learn to identify the different parts of speech, such as nouns, verbs and adjectives. So, in the study of Color, we must first be able to identify the different Color tones of the Chromatic Circle. After that, we are ready to investigate the different forms, or manifestations, of each Color. Color is strangely like language, in its different forms and shades of meaning. It has different qualifiers and modifiers. One of these qualifiers is known as Value. We should understand clearly what this means.

We have already learned that the Colors in the Chromatic Circle, as shown in the Charts, are seen in their full strength or intensity. But in the world about us we often see any one of these colors in lighter and in darker tones. We can easily recall a large family of blues, reds, greens and all the other colors, ranging from very pale to very dark tones. This quality of lightness or darkness is what we mean by Value. If I say to you "I shall wear a blue dress tomorrow," you do not know whether I mean a light blue, a dark blue or a normal blue dress. But if I say, "I shall wear a dark blue dress tomorrow," you immediately form an idea of what I mean. But you do not know just how dark my dress will be, for there are many degrees of dark, in blue. It is often necessary to state exactly how dark or how light a certain Color tone is. To help us do this, a scale of values has been prepared, each step in the scale having its own particular name, just as in the scale of music we have the notes or tones do, re, mi, fa, sol, la, si, do. The middle scale of values facing Page 20 is expressed only in grays, and is known as the Neutral 
Value Scale, but it would be possible to show the same gradation of tints and shades of any Color, ranging from the palest tint you can imagine to the deepest shade. The palest tint would be nearest white, and the darkest shade nearest black.

Black and white, in mixture, give us neutral grays,-that is, the grays that show no tinge of color. If to white we add a touch of black, we shall produce a very light tint of gray. If we add more black we shall produce a darker gray. Between white and black there is an infinite number of steps or degrees of gray. It is impossible to show them all, so a scale of seven steps has been adopted as the standard or symbol for all the grays between white and black. Beginning with white, these steps have been named, just as we have named the steps in the musical scale. (Facing Page 9.)

"Middle" is found half way between white and black.

"Light" is between "Middle" and White.

"Low Light" is between "Middle" and "Light."

"High Light" is between "Light" and White.

"Dark" is between "Middle" and Black.

"Low Dark" between "Dark" and Black.

"High Dark" is between "Dark" and "Middle."

When we wish to classify and name the Value of a color tone, we may do so by comparing the lightness or darkness of that Color with a step in the Neutral Value Scale. We can say Red at High Light, if we mean a pale tone of red, or Red at High Dark, if we mean a tone of red that is a little darker than the normal. In this way we can locate the lightness or darkness of any Color tone.

In the Value Scale shown facing page 9, two colors, blue-green and red-orange, are arranged in graded tones on either side of the Neutral Scale. Observe that both of these colors show their full intensities at Middle Value. There are other colors, however, whose full intensities would be located at different degrees of the Value Scale, for all colors at full intensity (as seen in the Chromatic Circle) are not of the same value. For example, yellow at full intensity is much lighter in value than blue or red in full intensity. Of all colors, yellow is the lightest in value and violet is the darkest. Yellow at full intensity is at High Light in value, and violet at full intensity is at Low Dark. Lighter tints of yellow 

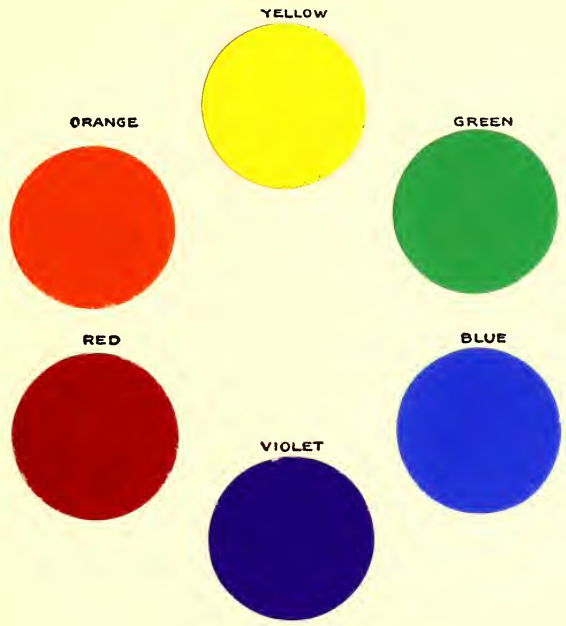

NORMAL COLORS AND TINTS

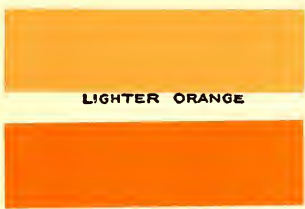

LIGHT ORANGE

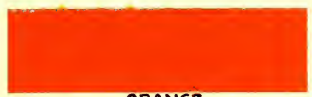

ORANGE

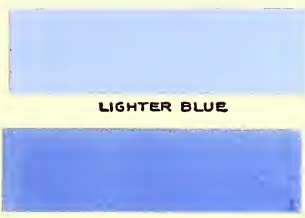

LIGHT BLE

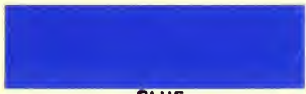

BLUE 

would, therefore, pass out of the range of the scale of Neutral Values which is shown (facing page 9). Of course, the number of steps in any Value Scale could be infinitely increased, as a color "travels" toward white or black, and new terms could be added to indicate any degree of lightness or darkness presented by a color tone.

In ordinary usage, however, we speak of the Values of Color as Tints and Shades of that Color. Any tone of red, for example, that is lighter than normal red, is a Tint of red. Any tone of red that is darker than the normal is a Shade of red. People are often careless in their use of the terms Tint and Shade. They frequently speak of light shades of a color when they really mean Tints. The term "Tone" includes all Tints, Shades and the Normal of a Color. Therefore, it would be proper to speak of many Tones of blue, for instance, ranging from pale blue to dark blue, when the word "Shades" used in this sense would be incorrect.

Tints are made by the addition of white (or in Water Color by the addition of water) to a normal tone of Color. Shades are made by the addition of black to the normal tone. Chart No. III shows the six leading Colors, and below the circle are given the Normal and two Tints of orange and blue. Chart No. IV shows under the circle a Normal, a Tint and a Shade of two Colors, yellow and blue.

The idea of Tints and Shades may be demonstrated before a class by using the Color solutions in glasses before referred to. In an empty glass, pour a little of the strong red, yellow or blue solution. Add water to this, until a distinctly lighter tone is observed. Add more water for still lighter Tints. This experiment can be carried as far as desired, until no Color is discernible in the water. Into another empty glass pour a little of the normal solution. Add a little black (made by dissolving two hard cakes in water). This fusion of black with the normal will result in a Shade of the Color. Add more black in the same glass or in another glass until a number of Shades of the Color are produced.

The making of Tints and Shades of the Primary and Binary colors through the use of Water Color washes is not too difficult for pupils in third and fourth grades. There are many interesting exercises involving the use of different Color values which may be presented to young students. It is recommended that in grades when a definite study is made of these Color qualities, the employment of Colors for decorative pur- 
poses should be limited to the Primaries and Binaries with their Tints and Shades, in combination with the neutrals. Limitations stimulate invention and intensify emphasis upon certain specific points.

Interesting landscape effects may be obtained by the use of light and dark values of a single color. A pale sky, a foreground of middle value, suggesting a field or a hillside, with tree shapes in dark value rising against the light sky, would be effective in neutral grays, in blues, in greens, or in any other color. The various tints and shapes of colored papers which are now available offer a fine medium for such arrangements. The same design or composition can be carried out in a variety of different arrangements of values, and the difference in effects observed. An understanding of the different results produced by the use of strong contrasts of value, by the use of values that are closely related, and by the use of different colors of the same or of widely different values is most necessary to success in Design. 


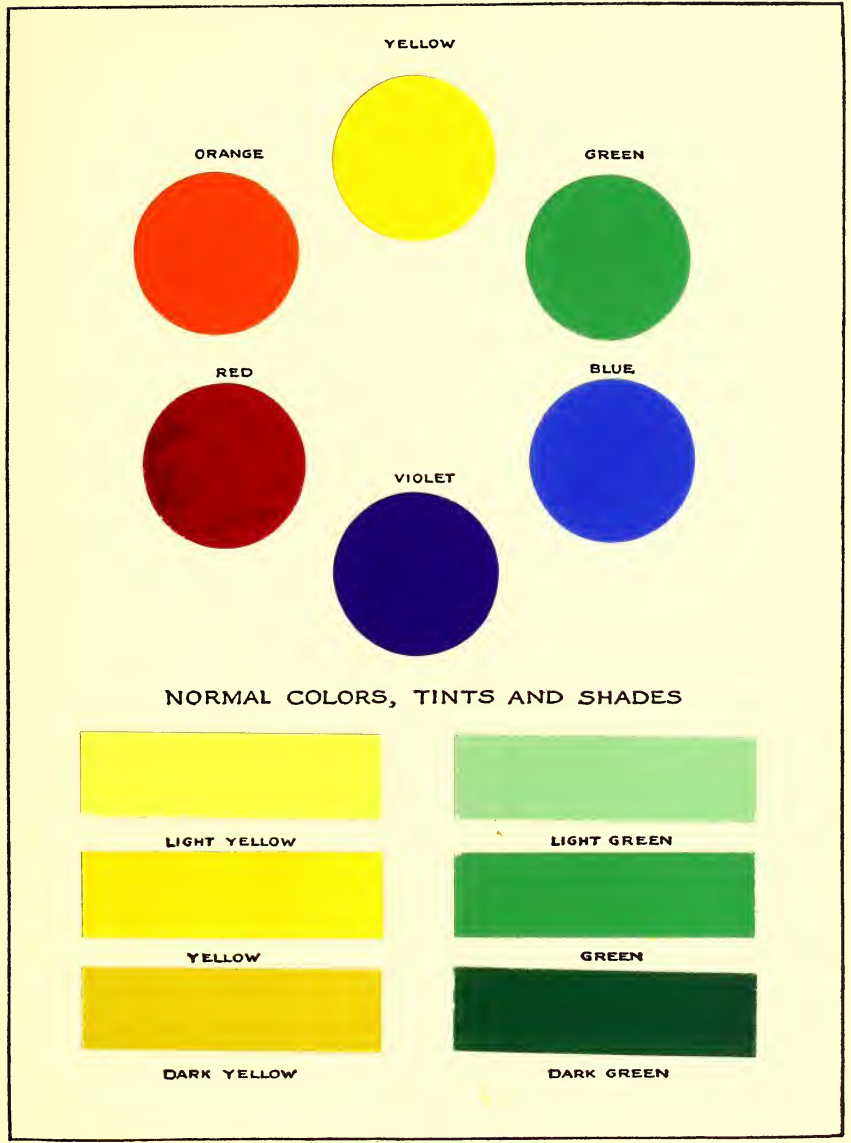

CHART FOUR 



\section{Chapter VI}

\section{COMPLEMENTARY COLORS AND HOW TO USE THEM}

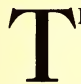

HE Primary and Binary Colors as they appear in Charts II to $\mathrm{V}$, are often spoken of as the six leading Colors, because in their individual tones they express the principal steps or stages in the passage of Colors around the Chromatic Circle.

These leading Colors have different relationships to each other, just as a verb in a sentence has a certain relationship to a noun and another relationship to an adverb. We shall speak first about the relationship which Complementary Colors bear to each other.

The three Binaries, orange, green and violet, are each made by combining equal portions of two Primaries. Orange, for example, is made up of equal parts of yellow and red. In orange, therefore, one of the elements of color is lacking-the element of blue. Blue is the one thing needed by orange to complete the Color circuit. Blue is therefore said to be Complementary to orange. Again, violet is made up of equal parts of red and blue. The Color element lacking in violet is yellow. Therefore, violet and yellow are Complementary to each other. Green being made of a combination of equal parts of blue and yellow, needs red to complete the circuit. Therefore, in these pigment combinations, red and green are Complementary to each other.

Complementary Colors are in the strongest possible contrast to each other. You cannot think of a Color more different from orange than blue. They have nothing in common. They are as unlike as it is possible for Colors to be. Yet they have the peculiar power to enhance or enrich each other, when placed near together. An orange sky, at sunset, will "force" the blue of a distant building or of far hills; a red apple looks redder when it nestles among the green leaves of the tree, and a violet hat is intensified in color if a yellow rose is placed upon it. You have doubtless tried the experiment of gazing intently at a circle of strong red Color, placed against a white background. If you suddenly remove the red circle and still continue to gaze at the white background, a green 
circle will appear. The eye will supply the complement to the Color that so filled it a moment before. Thus it is demonstrated that certain Colors seem to call for or demand certain other Colors. The study of these relationships is intensely interesting, and a knowledge of the influence of one Color upon another can be made of much practical value.

In the Color Circle shown in all the Charts except Chart No. I, the Colors are so arranged that Complementary pairs appear at opposite ends of the same diameters. In Chart $\mathrm{V}$, for example, yellow is diametrically opposite violet; orange is opposite blue, and green is opposite red. Through this arrangement in this and in the Charts that follow, it is easy to select the various Complementary pairs.

Though when placed near together, Complementary Colors possess the power of enriching each other, in mixture the effect of their combination is just the opposite. If in an empty glass we pour an equal amount of orange solution and blue solution, the tone produced is neither orange nor blue, but gray,-Neutral Gray! The same is true in mixtures of equal parts of yellow and violet, and of red and green. This explains the presence in Chart V. of the central circle of Neutral Gray. Observe that this Neutral Gray circle is half way between all the pairs of Complementary Colors that are shown. It means that equal portions of two colors that are Complementary to each other, will, in mixture, completely neutralize each other.

In our work we can utilize this scientific fact, in a variety of ways. If equal parts of a Complementary pair of Colors will produce Neutral Gray, a smaller proportion of one Color would soften or "gray" the other. For example, if we wish to reduce the brightness or intensity of a green tone, in paint, we add a little red, and the desired effect is gained. Similarly, we soften or "gray" a too brilliant red, by adding a little of its complement, green. The rectangle of gray-red in Chart V. was produced in this way. So were the other rectangles, labelled respectively gray green, gray yellow, gray violet, gray blue and gray orange. Each "grayed" Color was produced by adding a bit of its Complement.

At this stage of the definite study of Color, students may be permitted to use Complementary colors in decorative arrangements. If normal tones of orange and blue, violet and yellow, or red and green are used, it should be in small quantities, upon backgrounds of black, white 


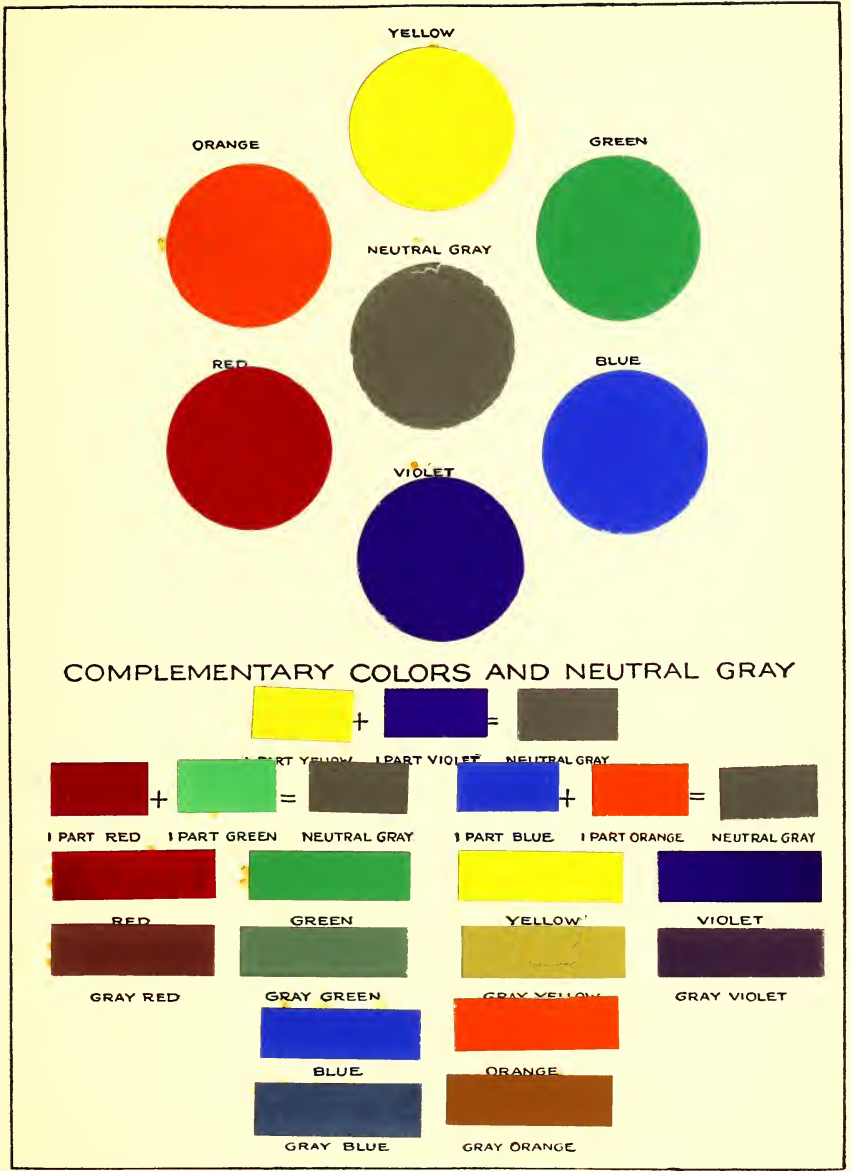

CHART FIVE 


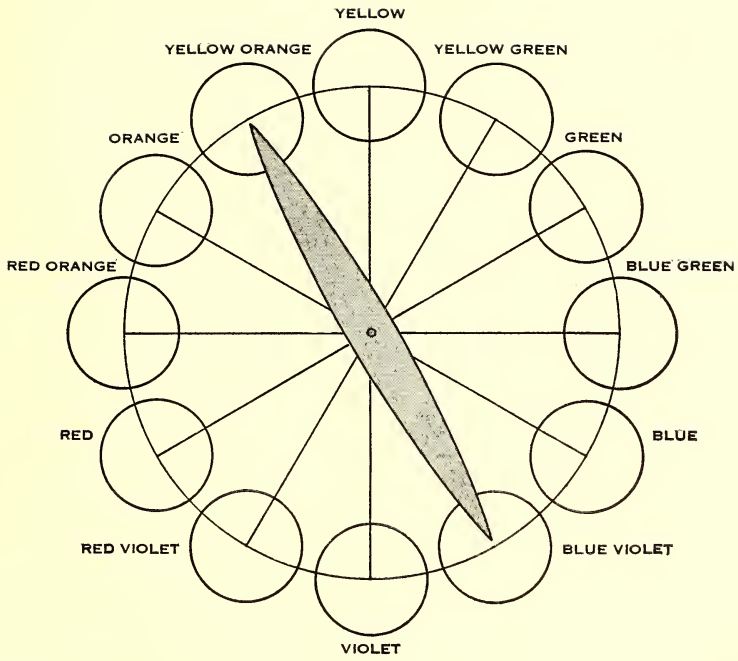

A DEVICE FOR LOCATING COMPLEMENTARY PAIRS OF COLORS

FIGURE ONE 
or gray, or in some other form of combination with the neutral tones. In the popular stick printed designs upon black, white or gray paper, the full strength of Complementary Colors may be used, for stick printing is limited to the use of small spots of Color, and these can be perfectly balanced by the judicious use of Neutrals. In our costumes, however, nothing could be more hideous than glaring combinations, in large quantities, of these Complementary pairs. A red waist with a skirt of normal green, a blue suit with a superabundance of orange trimming, or a velvet wrap of normal violet with yellow fur trimming would offend the refined taste, and render the wearer uncomfortably conspicuous. As in everything else, a little Color knowledge is a dangerous thing. We should "play safe" until we have gained, through experience, the knowledge that will develop judgment and will also develop that mysterious but highly important quality which we call taste.

A simple device for locating Complementary pairs of Colors is shown in Fig. 1. A pointer has been cut of thin cardboard and attached by a thumb-tack to the center of the Color Chart. This pointer turns easily on its pivot and its ends indicate the different pairs of Colors that are complementary to each other. 


\section{Chapter VII}

\section{NEIGHBORING OR ANALOGOUS COLORS}

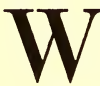

E can see that each of the six leading Colors-the three Primaries and the three Binaries-possess a strongly individual Color characteristic. It is easy for nearly everyone to distinguish yellow from orange, orange from red, and red from violet, etc.

This distinguishing Color quality is, like Value, one of the essential properties or qualities of Color. We speak of it as Hue. It is Hue that makes yellow distinguishable from orange, or that enables one to distinguish blue from green. We know that in the world about us there are many Hues that are not shown in our Charts. Let us see if we can find out how to classify and name these different Colors, just as we discovered in Chapter Five how to classify and name the different values of Color.

Chart VI, shows six more Colors than have been given in the five preceding Charts. You will notice that each of these new Colors is placed between a Primary and a Binary, in the Chart. You can guess how the new Color is made. Equal parts of the Primary Color (as for example, yellow), and the binary color (as orange), have been mixed to produce the new Color, or Hue (for example, yellow-orange). In this way were formed all of the new Hues that appear in the Chart. They are named yellow-orange, red-orange, red-violet, blue-violet, bluegreen and yellow-green.

In actual practice, there is a much more convenient way of mixing the different Hues of Color. This is suggested by the Color "equations," given below the Chromatic Circle in Chart VI. Imagine that each Primary Color circle in the Chart is made up of four equal parts. If we take three parts of yellow and one part of red, we shall produce the same result that we found in mixing equal parts of orange and yellow,-yelloworange. If we take three parts of red and one part of yellow, the result 


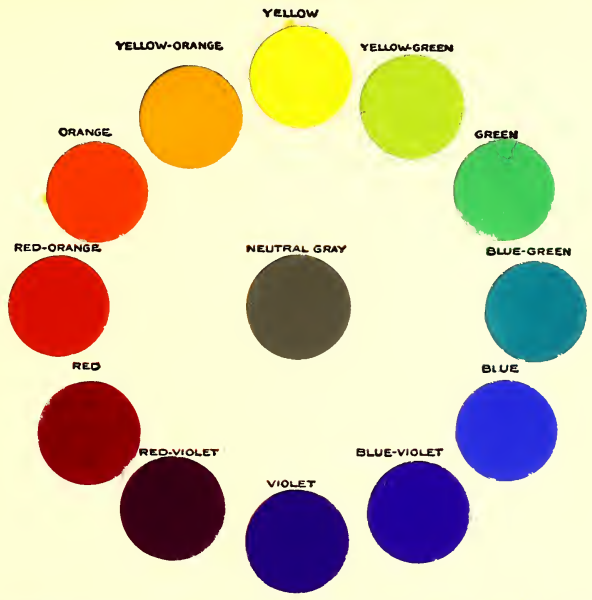

PRIMARY COLORS BINARY COLORS AND HUES

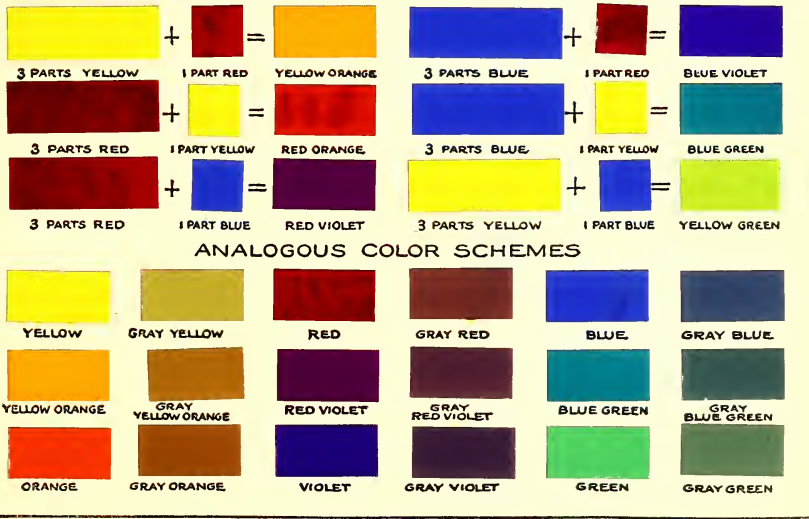


든 
will be red-orange. Three parts of red and one part of blue make redviolet. Three parts of blue and one part of yellow make blue-green. Three parts of yellow and one part of blue make yellow-green. These Hues are named from the Primary Color that dominates them. The actual mixing and spreading of these different Hues of Color is highly essential to a thorough understanding of their origin and of their relationships.

All of these facts about Color, interesting as they are, will be of small service to us unless we use them. That is what all knowledge is for,- - to be used! Let us see how these new and beautiful Hues of Color can be made helpful, in enriching our Color vocabulary and in making that vocabulary express our ideas of beautiful Color combinations.

When a certain Color is present in each of several Hues, as, for example, yellow is present in yellow, orange and in red-orange, there is a certain relationship established, just as exists between brothers and sisters of the same family. Yellow is a "blood relation" of any other Color that contains yellow. It is not a "blood relation" of red or blue. Yellow, red and blue are the founders of three separate and distinct families, and they, themselves, have nothing in common. We call those Colors that contain a common element analogous. In the Chart, analogous colors are placed as neighbors in the circle. Because of this position, they are sometimes called "neighboring" or analogous Colors, and this, also, expresses their relationship, or harmony in a way that we can all understand.

Since a common element in each group of Colors can be depended upon to produce harmony we are safe in choosing Analogous or Neighboring Colors for a Color scheme. This explains the reason for the vertical rows of Colors, under the caption "Analogous Color Schemes," in Chart VI. Yellow, yellow-orange and orange, in full intensity, are given, as a scheme that may safely be used, in places where such brilliant coloring is appropriate; always remembering the balance that must be kept by using these intense Colors with a proper amount of neutral white, black or gray. The scheme of these same Colors, grayed, is fully as beautiful, but in a quite different way. We could use the grayed Colors in much larger quantities, as in room furnishings or costumes, and feel 
that we had not offended good taste. The same is true of the other two groups of Analogous Colors given in the Chart. Intense red, red-violet and violet suggest a rich and gorgeous scheme for certain decorative purposes. A bed of dahlias shows us these same colorings. Plucked from their parent stalks and arranged in a vase that continues or completes the wonderful harmony, their decorative value in a room is enormous. But who would think of hanging bright red curtains in a room with red-violet walls, and placing in that same room a rug of intense violet on the floor? The grayed scheme of violets, however, suggest charming effects for costumes or furnishings.

It is interesting to know that these grayed effects are produced by adding to each Color a little of its complement. In the last chapter we learned that each Primary had its Complement in a Binary, and that these pairs, in mixture, neutralized or grayed each other. In this larger Chromatic Circle (Chart VI.) each Color has also its Complement, found at the opposite end of the same diameter. For example, blueviolet is the complement of yellow-orange; yellow-green is the complement of red-violet; and red-orange is the complement of blue-green.

While to produce grayed Color the law of adding to any Color a touch of its Complement holds good invariably, the designer in common practice, usually adds black to any Color which he wishes to gray. This is a "short cut" which in the decorative use of Color it is quite legitimate to employ. 


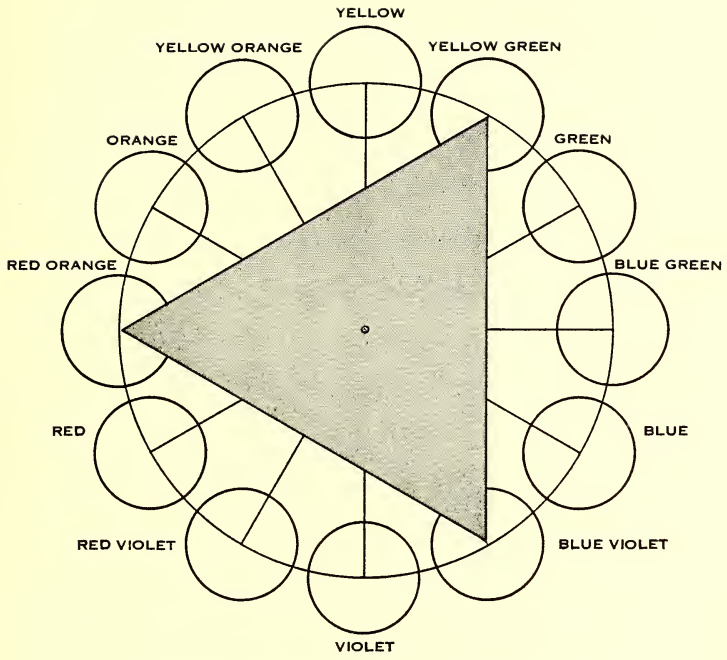

A DEVICE FOR LOCATING A COLOR TRIAD

FIGURE TWO 


\section{Chapter VIII}

\section{THE COLOR TRIAD AND THE SPLIT COMPLEMENT}

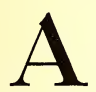

COLOR SCHEME is a group of Colors harmoniously related to each other, and which is suitable for use in a design or in materials of any kind. Nature furnishes us with innumerable combinations and groups of Colors, of ten of wonderful interest and beauty. But the conditions under which these combinations are used in Nature are not the conditions that we are under when we try to furnish a room or plan a costume. Therefore, a blind or purely imitative following of Nature's schemes will of ten lead us to disaster, in our applications or uses of Color.

The chief value of employing a Color Chart in determining Color schemes is that this practice makes us think about Color. It is not enough to "feel" the beauty of certain Color combinations; we must think as well as feel, and be able to give reasons for our Color sensations. The more we think about Color the greater will be the development of our Color sense, and the more will we be able to enjoy the feeling and emotions that are produced in us by Color.

Through our study of the Chromatic Circle we now understand that there are several distinct ways of combining Colors, each of which can be depended upon to produce beauty. We have learned, in the first place, that two Primary Colors should not be combined, but that any one Primary in any degree of intensity, may be combined with black, white or with any mixture of black and white,-in other words, with Neutral gray. This is the simplest Color scheming that we know.

We next found that any one Color was capable of an infinite number of Values, and that any two or more Values of a Color could be safely used together. Such a group is called a self-toned or Monochromatic scheme. It is always safe, always unobtrusive, never as interesting as groups that contain two or more colors. From Tints and Shades or Values or Color we take the next and vastly more significant step to the 
use of Complementary Color schemes, which is the attainment of harmony through unlikeness, or contrast.

When we use a pair of Complementary Colors, in any Value or intensity, we really combine portions of the three Color elements, yellow, red and blue. In combining blue and orange, for instance, we have one element, alone, in blue, and the two other elements, yellow and red, in orange. The same is true of violet and yellow, of red and green, and of all the other pairs of Complementary Colors.

It is true that the eye is better satisfied with a group of Colors that shows, in some degree, all of the Color elements. In our Color sensations, the presence of all three elements seems to complete the Color circuit. Why this is true, we cannot here explain. It must be accepted as a fact.

There are other ways of arriving at a combination of the three Color elements in a group. One of these is through the use of a Color "triad." A triad is a union or group of three, and is a term that we have borrowed from the nomenclature of music. We cannot take, at random, any selection of three Colors from the Chart; the Colors of our choice must be at equal intervals from each other. This again, finds an analogy in music. The device of the equilateral triangle will insure an equal distance between our color steps. (Fig. 2.) If we place the triangle with its apex on yellow, the position of the two opposite angles, will locate the other two colors in our scheme-red and blue (Fig. 2). If we turn the triangle on a pivot to the left, placing its apex on yellow-orange, we shall locate another and more interesting triad,-yellow-orange, red-violet and blue-green. Still turning our triangle to the left, we locate the triad of binaries, - - orange, violet and green. So, in our journey around the dial of the Colors, we can locate several different and very interesting groups, all resulting in a Color scheme of triads. The three Colors in each group may be used together, in any value or intensity, with white, black or neutral gray, and can be depended upon to produce harmony.

Another means of arriving at a Color scheme that combines in still more subtle proportions, the three elements of Color, is through the use of the "Split Complement." This is also best explained and used by means of a device. (Fig. 3.) An isosceles triangle, (a triangle having two equal sides), whose base is equal to the distance between the centers 


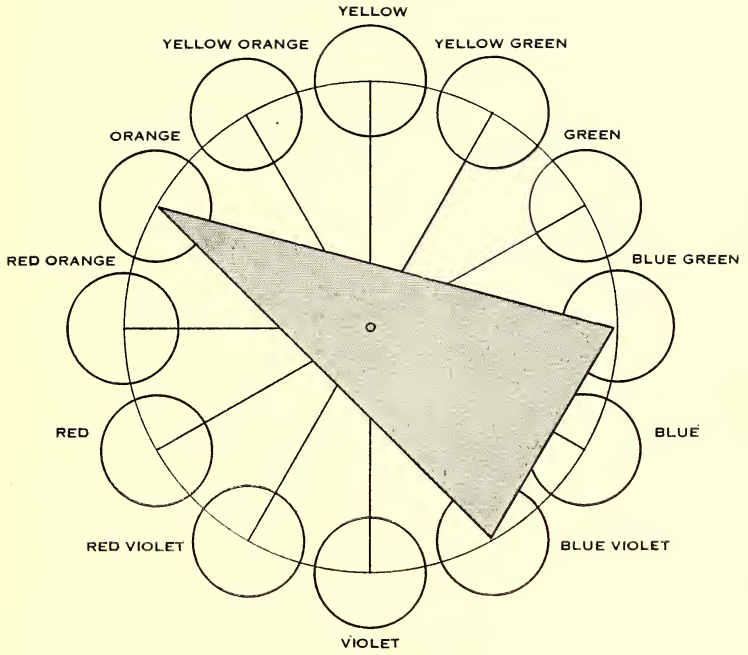

A DEVICE FOR LOCATING A SPLIT COMPLEMENT

FIGURE THREE 

of the small Color circles, is placed so that the apex is at violet, for instance. The Complement of violet is yellow. The position of the two opposite angles of the triangle will locate a Color on each side of yellow, yellow-orange on the left and yellow-green on the right. The three Colors, yellow, yellow-orange, and yellow-green form a "Split" Complement. They contain all the elements of the straight Complement, but in different proportions. The less obvious these Color elements are, the more "quality" do the different tones seem to possess.

The isosceles, like the equilateral, triangle can be made to travel around the Color Circle, pointing out the different harmonies of Split Complements that are possible with the twelve Colors of the chromatic circle. In individual or class room practice, the actual presence on the Chart of a paper triangle will greatly assist the quick detection of the different Colors in these schemes. The experienced designer can no more dispense with his Color Chart and its devices than can the musician dispence with the keyboard of his piano. 
Chapter IX

\section{COLORS IN VARIOUS DEGREES OF INTENSITY-}

\section{OR GRAYED COLORS}

DHERE are three modes or changes through which a Color may pass. Each of these modes affects Color quality. Therefore, we 1 say that Color has three properties, or dimensions, by means of which it may be measured, classified, and named. The first of these properties we call Hue; the next, Value; the third Intensity. Some authorities speak of this third property as "Chroma."

In Charts VI. and VII. we may begin at any Color, as yellow, and pass by successive changes in Hue to yellow-green, to green, to bluegreen and so on around the circle. It is the change in Hue that makes this passage possible. We can in this way locate any Color, as to its Hue, by reference to the Color Chart.

We have learned, also, that we can make a graded scale of any one Color, in its passage from normal to light, from normal to dark, or from the darkest to the lightest tone of that Color. This property of lightness or darkness we have learned to call Value. Every Color tone must of necessity possess the property of Value, and this quality can also be classified and named, by reference to the Value Scale.

Charts VII. and VIII. illustrate the third property of Color,-Intensity. In passing from the outer circles in these Charts on a diameter to the center, we see that the Color tones grow less bright, less intense. This passage from bright to gray is what we mean by Intensity. There are as many different degrees of Intensity as the eye can detect. These Charts are but symbols of the infinite degrees of grayed color, just as the Value scale is a symbol of the infinite number of neutral gray tones that can be produced. Chart VII. shows but three degrees of Intensity of each of the six leading Colors. The outer circle of yellow, for example, is in full strength, or full Intensity, as we say. Immediately under it is a tone of yellow whose brightness is reduced one-half. This we call gray-yellow, but if we wished to be scientifically accurate in naming it 


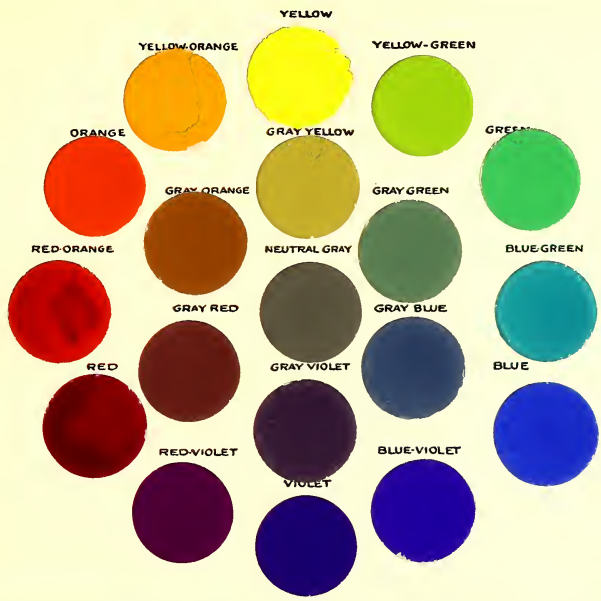

\section{COLORS IN FULL INTENSITY AND GRAYED COLORS}

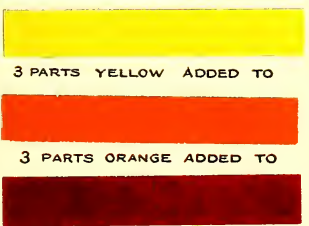

3 PARTS RED ADDED TO

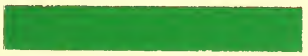

3 PARTS GREEN ADDED TO

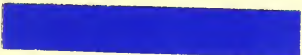

3 PARTS BLUE ADDED TO

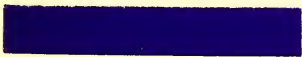

3 PARTS VIOLET ADDED TO

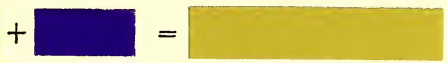

I PART VIOLET

MAKE GRAY YELLOW

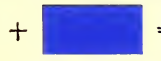

- part elue
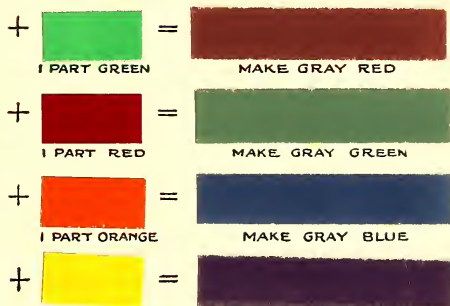

I part yellow
MAKE GRAY RED

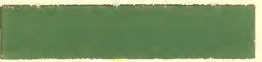

MAKE GRAY GREEN

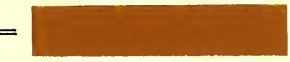

MAKE GRAY ORANGE

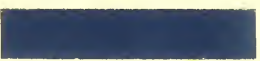

MAKE GRAY BLUE

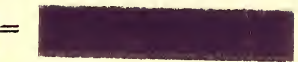

MAKE GRAY VIOLET 

we should call it yellow at one-half intensity. The middle circle of Neutral Gray shows what will happen to yellow when its intensity is completely neutralized. All of its individuality is gone, and it has become neutral gray.

In previous chapters we have learned that a Color is neutralized or grayed by the addition of its complement. The schedule of Colors placed below the Chromatic Circle in Chart VII. gives the proportions that were used to produce the grayed tones shown in the column at the right. These are the proportions that were used in making the halfintense tones in the Color Circle above.

Chart VIII. shows on its outer row of circles all the twelve Colors in half-intensity. Six of the Colors have been reduced still more, and are shown in one-quarter intensity. All degrees of intensity end in Neutral Gray.

We can produce absolute neutrality, as we have seen, by mixing equal strengths of Complementary Colors. If we add less than an equal amount of the complement to a Color, we shall produce some degree of grayness of that Color.

The Color schemes given below the Color Circle in Chart VIII. show that the laws of Color harmonies exist in grayed tones, just as vitally as they do in schemes of intense Colors. We may use Tints and Shades of grayed Colors (See Monochromatic Color Schemes, in Chart VIII.) and obtain beautiful effects. So, in combining the Hues of Color in analogous schemes, we may select the grayed instead of the intense tones, according to our purpose. The Complementary Colors, grayed, are familiar combinations.

A beginner in the study of Water Color painting once drew a faithful outline sketch of a growth of a red rose. She desired to color her drawing. She painted the flower red, from the red cake of Color in her box, and the leaves green. The instructor smiled when he saw her work. "Your rose is indeed unlovely," he said. "Put a little green in your red and a little red in your green, and you will be sure of harmony." 


\section{Chapter X}

\section{THE PSYCHOLOGY OF COLOR}

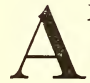

NY means of expressing or communicating one's thoughts or feelings may be called a language. If, in using spoken or written words, we understand the different shades of meaning that the wonderful English language represents, we shall be able to express our ideas accurately and beautifully. People will enjoy our speech, if we convey by means of carefully chosen words, exactly the ideas that are in our minds. How handicapped we feel, when we cannot find words to express our thoughts! In a foreign country, we may be greatly embarrassed because we cannot convey, in the language of the realm, an idea of our simplest needs. We cannot ask the way to the station, or tell the waiter what we would like to eat, without subjecting ourselves to ridicule. Such a situation makes us most uncomfortable.

So in the realm of Color, we either bungle and jumble, or else we hesitate and fail to express ourselves, for fear of making mistakes. Yet a knowledge of the marvelous language of Color is within the reach of all, and with this knowledge will come a freedom and delight in the use of Color.

All that we have learned in our study of the Color Charts in this book will help us to express ideas about Color. Yet there is another phase of Color study which the Charts cannot touch. This "inner shrine" of Color we may call its psychology. We understand that psychology in general has to do with spiritual laws rather than with physical science. So, quite apart from a consideration of the sources of Color and of its component parts, its properties or dimensions and even of its harmonies is the question of the effects that different Colors exert upon our feelings and emotions. Why, for instance, is red a more exciting Color than blue? Why are orange and yellow stimulating, and blue and green quieting? Why do we feel cheered and enlivened by light tones of Color and depressed and weighted down by dark tones? Why do we speak of some Colors as "warm" and of other Colors as "cool," when 
there is no physical sensation of heat or cold? Why are yellow, orange and red called "advancing" colors and blue and violet "retreating" colors? All these and many other questions are answered in the study of Color psychology.

The human eye loves Color. Whether they know it or not, all people react or respond to the influence of Color. The degree of their reaction varies greatly, for some people are naturally much more sensitive to Color than others. But all are susceptible to its influence. Color has power to attract attention, to stimulate emotion, to cheer and animate, or to quiet and subdue.

Each Color has a meaning. It exerts upon us its own particular influence, different from the influence of other Colors. Let us analyze a few of the Colors in our Charts, and try to find out something about their psychological attributes.

Of all the Color elements, we can see that yellow most closely resembles light. We speak of it as "sunny," and we feel its cheerful, buoyant personality. We recall the hopeful forsythia of early spring, the cheerful buttercups, the jocund daffodils-immortalized by Wordsworth -the sunny dandelion and a host of other yellow flowers, bearing a particular message of light and cheer, because they are yellow! Yellow is the symbol of the sun, with its life-giving radiance and its power to dispel gloom. Let us remember this psychological quality of yellow, when we paint and paper a room that has insufficient light from outside. Any Color scheme containing a dominant note of yellow, as shown in a "trim" of ivory white, gray yellow-orange walls, a creamy ceiling and a light brown rug, will reflect all the light that comes in through the window and will seem to add a certain element of light, all its own.

Red, the second Color element, gives us the feeling of vitality and warmth. It is the symbol of action and of courage. "Called to the Colors" is a significant phrase, and we may be sure that the "Colors" contain a strong element of red, as in our own flag. Red stimulates and excites. When we are stirred with strong emotions, the red blood leaps from our hearts and flames in our cheeks. Red is stronger in its attractive force than yellow and it supplies an element of thought of heat, which is lacking in yellow. Who has not felt the cockles of his heart warm and expand before an open fire? In a room otherwise dark 
and gloomy, it seems a living thing. The people of the house draw near to it. The cat curls up before it. The dog draws a long breath of content and stretches his head toward it. It is partly the crackle and the heat but it is most of all the warm, vital color of the flames that attracts and cheers us. Sir Gilbert K. Chesterton has expressed our attitude toward an open fire in these characteristic words:

"A queer fancy seems to be current that an open fire exists to warm people! It exists to warm their hearts, to light their darkness, to raise their spirits, to toast their muffins, to air their rooms, to cook their chestnuts, to tell stories to their children, to make checkered shadows on their walls, to boil their hurried kettles, and to be the red heart of a man's house and hearth, for which as the great heathen said, a man should die."

We can easily see why it is that red is called a "warm" Color, and why all Colors that contain red as a constituent seem to be warmed by its presence. Therefore, in our costumes and furnishings we should remember the psychology of red. Too much of it, as in a bright red waist or coat, will render the wearer unpleasantly conspicuous, and might irritate to a dangerous degree a person of super-sensitive temperament! In a room where much coziness and warmth is desired, as in a library, red tones might with discretion, be employed; but in a dining room already warmed by light from south windows, red as a dominating factor in the color scheme would be disastrous, especially on a hot day!

The third element of Color, blue, has a distinct individuality. It is not sunny, it is not warm, it is not aggressive. Blue is everything which red and yellow are not. It is cold, quiet and reserved. We speak of the icy, blue stillness of the far North; of cold, steely blue eyes; of having "the blues" when we are conscious of a lack of enthusiasm over life's affairs. Blue, as we have learned, neutralizes, or grays its opposite, orange. Blue is modest and retiring, like the blue forget-me-not and the fringed gentian that only blooms in secluded places. Because of its quietness and restraint, blue has a large place in our schemes of house furnishing, costuming and commercial designing. It is a balance wheel for yellow and red. Often we desire to furnish a room in very quiet tones, as in a bedroom; or we need a room of extreme formality, 


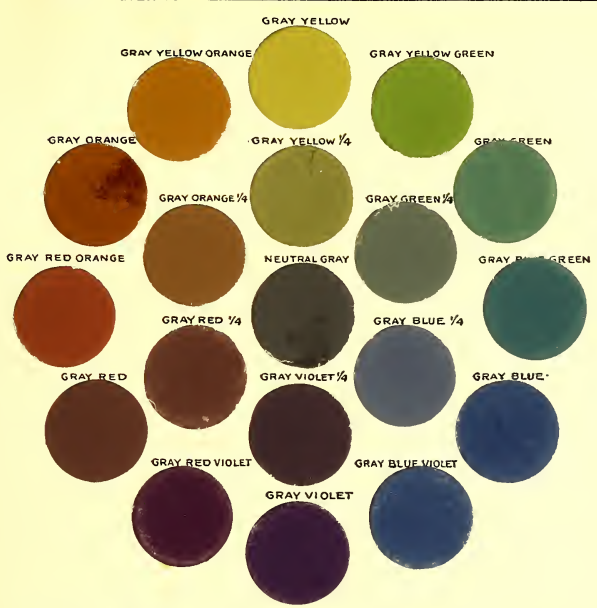

COLORS IN ONE-HALF AND IN ONE-FOURTH INTENSITIES MONOCHROMATIC COLOR SCHEMES

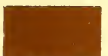

GRAY ORANGE

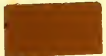

GRAY ORANGE

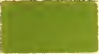

YELLOROY OREEN

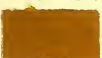

cotar

YELLOWORANGE
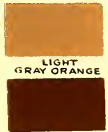

GRAY ORANGE

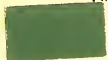

GRAY GREEN

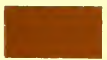

GRAY ORANGE
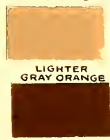

OARKER

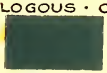

GRAY

BLUE GREEN

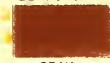

RED ORANGE COMPLEMENTAR

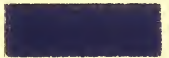

grat BLUE VIOLET

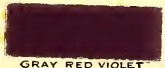

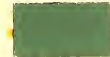

GRAYGREEN

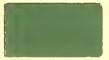

GRAYGREEN

- SCHEMES
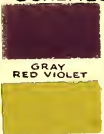

GRAY YELLOW
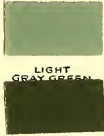
DARK
GRAYGREEN

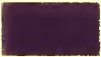

GRAY VIOLET

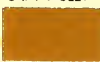

YELIOWOYKANGE

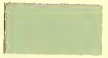

LIGHTER

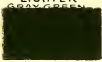
DARKER
GRAY GREEN

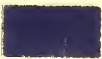

GRAY

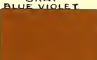

GRAY ORANGE

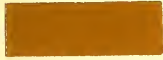

GRAY YELLOW ORANGE

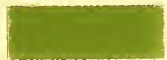

ORRYY YECLOW GREEN

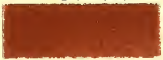

GRAY RED ORANGE

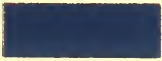

GRAY BLUE

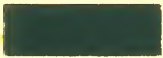

GRAY BLUE GREEN

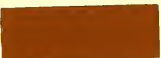

GRAY ORANGE 

as a parlor for state occasions or a drawing room. In such instances, we may well select blue as the dominating note in our scheme.

Since the three elementary Colors are so different in their effect upon our emotions, it is interesting to see the psychological result of mixtures. The Binary Colors may be cited as examples. Orange is not so light as yellow, nor so aggressive as red, yet it partakes of the nature of both yellow and red. It has strong decorative quality, and it is of course classed with the warm colors. A small amount of intense orange, such as is supplied by a bowl of nasturtiums, a bit of embroidery or a piece of pottery will of ten redeem a room that is too blue, or too monotonously brown. But it, like any other intense color must be controlled and balanced by large areas of subdued color tones.

Green, the combination of yellow and blue, shows the psychological tendencies of both components. It is lighter and more cheerful than blue, in effect, and has more dignity and repose than yellow. Green is restful to the eyes and nerves, is a relief from the warmth and heat of the summer sun, and is not depressing. In a south room, where there is more than a necessary amount of light and heat, green hangings and furnishings are most agreeable.

Violet is a combination of the vital aggressive Color, red, and the cold and dignified color blue. In equal quantities, these forces very nearly neutralize each other, but according to the predominance of red or blue, violet may be warm or cold, in its effect. Violet is the Color that is nearest to black, in value, and in its influence on our feelings. We can understand its use as "half-mourning." Violet and purple have always been associated with royal majesty, and have been accepted as the sign of imperial power. The toga of the Emperor in ancient Rome, or of any conqueror, in the day of his triumph, was purple. Violet in its darker tones denotes seriousness or solemnity. In its tints, which we call "lavender," "lilac," etc. there is a distinctly feminine quality marked by delicacy and refinement. It is perhaps less used decoratively, than any other color.

Starting with yellow at the top, the Colors of the chromatic circle fall into two groups: the warm colors on the left, and the cool colors on the right. We see, then, that certain groups of Analogous Colors, as yellow-orange, orange, and red-orange, will produce effects that are like 
these colors,-warm, rich, aggressive and of compelling force. Other groups, such as blue-green, blue and blue-violet, will produce effects that are like them,- -quiet, restful, serene. Certain groups, as the Complementary pairs, will present both warm and cool elements, as orange and blue. With such definite knowledge as this, we should be able to "prescribe" color schemes for different purposes and occasions, and to do so with intelligence and with confidence as to results. 


\section{Chapter XI}

\section{COLOR HARMONIES IN COSTUME}

70 reach its highest use, Art must be practical. Unless we can apply our knowledge of Color to the common activities of life, we miss the largest benefit and the greatest joy that such knowledge can give. The clothes that we wear proclaim our knowledge or our ignorance of the laws of Color harmonies, for clothes cannot be separated from Color, and we must of necessity select, buy and wear them. Although the question of Color is by no means unimportant in its relation to the clothes worn by men, we shall discuss first the question of Color as an element in the costumes of women.

In planning or selecting a costume for a woman, the first consideration is the person herself. Is she tall or short, stout or slender, darkskinned or light, full-colored or pale, with dark, light or "middle" hair? What is her temperament? Is she aggressive, retiring, positive or negative, vivacious or sedate?

After these questions have been settled, we may bring out our Color Chart, and try to relate our knowledge of Color harmonies to our subject. Every costume is in the beginning a problem in design, and one of the most important factors in the problem is the question of Color. We shall find that all of the scientific facts that we have accumulated about Color will come to our aid, and will help us to arrive at a safe conclusion.

One of the first harmonies of which we learned was the harmony resulting from the combination of one intense Color with white, black or gray. Let us see how this applies to costume.

As a general proposition, white is becoming to the great majority of people, and black is unbecoming to just as many. The reason for this is that white does not absorb color, and when worn next to the face, white permits the skin, the eyes, the hair, to appear at their full color value. For this reason, white makes a charming setting for the face, the hair, the eyes. The whole head becomes the center of interest. This is as it 
should be, for costume should act as a foil, to enhance attractiveness of the face, which is the seat of personality. Black does just the opposite. It soaks up or absorbs Color, and robs the complexion of its subtle Color tones, leaving it pale and gray. We should dismiss from our minds, forever, the idea that black is particularly suitable for people whose coloring is light toned, faded or gray. These are the very persons who should avoid black, next to the face, or in large quantities, in a costume. For them there are the beautiful gradations of colors, shown in Chart VIII., whose relationships to each other and to the wearer are so interesting and so important. The truth is that if black costumes are to be worn at all, it should be by persons of brilliant coloring, whose glowing faces, bright eyes and shining hair can more succesfully combat the depredations of the robber black!

Black and white when used together in a costume create the strongest possible contrast if employed in equal or nearly equal quantities. This makes the wearer most conspicuous. But a touch of black or white, or both, will often give accent or emphasis to a costume that might otherwise be tame. In a dark costume, a white collar will aid in attracting interest to the face, where interest should center. White gloves and shoes worn with a dark gown or coat will also attract the eye to those extremities. It is true that white shoes and a white feather on the hat will increase the apparent height of a figure, when worn with a dark costume, for the eye seeks out the patches of white and establishes its own line between them. Strong contrasts of Values or of Color tones always pull the eye in their direction, and must be used, in costume design, with the truth of this statement borne in mind.

In choosing a Color scheme for a costume, one should endeavor to determine her own personal scheme of Colors, - that which was given her by Nature-and she should build upon this as a foundation. Suppose, for example, that I have dark brown hair, dark eyes and a "dark" complexion. I am to be classed with the family of "oranges," for all browns are grayed tones of oranges and reds. I must turn, then, to Chart VIII., and look for suggestions for my costume at the lovely grayed yellow-oranges, oranges, and red-oranges. The law of complementary Colors tells me that I may also cross the circle and browse among the blues, the blue-greens and the blue-violets, possibly. My Value 
scale reminds me that there are many Tints and Shades of both oranges and blues, and so, according to my requirements, I may choose a light toned costume from these Colors for evening wear, a dark toned for street and business, or a middle toned for my spring suit. To relieve the monotony of these solid tones, I may choose trimmings or accessories of intense Color. These I may wear in my hat, in jewels, in bright embroidery, in a string of beads, or in a bag. I am also free to use white or black, or both, with any of these tones. Furs may also be made to help me in my problem. They may be white or black or toned with my costume, according to its needs.

If my eyes are blue and my hair is yellow, I may probably identify myself with the Complementary pair yellow and violet, or with any Analogous schemes containing these two Colors, although I must always remember that the Color and quality of my skin has fully as much to do with selecting a Color scheme as does the Color of eyes and hair. If my hair is auburn or reddish, I must remember the effect of green upon these warm shades. I know I shall be safe in "toning" my costume with my hair, and in selecting accessories and "notes" that will relieve my costume, and keep it from monotony. Thus does the Color Chart come to my aid, when I am seeking to solve the ever present and always interesting problem of dress.

Light tones of all Colors indicate cheerfulness, gayety, youthfulness, and buoyancy. This is why we instinctively select light values for evening wear. Middle values of the grayed Colors as a substitute for dark blues, greens and browns are sought by those who know how to tempt youth to linger beyond its appointed time, and white is seen to play an important part in the "make-up" of these costumes.

A Color is emphasized, frequently by the presence of a touch of the same Color in another part of the costume. Eyes that are blue, but too light, may be deepened by a touch of blue trimming near the face. Jewels and beads may be used to bring out latent color in this way. A color that is much grayed can be enlivened by an accent of its complement. A light neutral gray or a white dress makes a background against which any jewel or any Color can be worn with fine effect.

The rigid conventions that control the costumes of men make it almost impossible to express any but the most limited Color harmonies in 
the selection of their clothes. Black, dark blue, brown and a variety of sober grays are almost the only choices that are open to men. In summer a wider range is offered in the various light grays, $\tan$ and white materials. The vogue for these lighter tones has greatly increased of late. This is much to be desired, for what has been said regarding the general effect of light tones upon the wearer applies to men as well as to women. If the introduction of a wider range of "lively" gray mixtures in suits for men's general wear could be accomplished, another step in the right direction would be taken. At present, a man may express his appreciation of Color harmony only in the choice of his scarf. Limited though his opportunities may be, the principles of color harmony, heretofore explained, should be followed. A man is often judged by the tie that he wears! 


\section{Chapter XII}

\section{COLOR HARMONIES IN INTERIOR DECORATIONS}

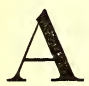

DEPARTMENT store in a large town recently displayed in a show window a number of so-called Japanese vases. They were about fourteen inches high, of fairly good proportion and they were decorated. The decorations were of the "decadent" Japanese type, made for the American market. They consisted of realistic pictures of birds, flowers, butterflies, fishes, clouds, mountains and a variety of landscape effects, painted on backgrounds of "shaded" red, violet, green and other colors. A card in the window conveyed the information that these vases would be sold at the opening hour on a certain day at the astoundingly low price of one dollar! Long before the hour designated, the sidewalk in front of the store was crowded with would-be buyers. When the doors swung open, the people rushed to the sale counters and each one seized as many of the vases as he could carry, eager to pay his money for what he considered beautiful. A teacher of Art, who had seen the display in the window and had hoped that the vases would find few purchasers, was much discouraged that the standards of the public taste proved to be so low.

"How can these people like them?" she said. "For years we have taught Art in the schools, probably to these very people, and apparently we have made no impression on them."

The friend to whom she expressed her disappointment remarked that the case was not so hopeless as it seemed.

"It would be worse if they had no interest whatever in vases," he said. "They are willing to pay their dollars for what to them is beautiful. What they need is training and instruction, that their standards may be raised. That is the important thing. Our instruction in the past has not equipped these people to discriminate between good and bad design, nor to analyze color schemes. They have no standards other than realism, and they see no reason why realism, so beautiful in nature, is not also beautiful upon these vases." 
The people who bought the unlovely vases expressed by their act their ignorance. Every purchaser of any article inevitably expresses himself. Our clothes, our houses, the things with which we surround ourselves, speak eloquently of what we are. We cannot disguise our standards of taste. It is of the utmost importance to us as individuals, and to America as a Nation, that our ability to appreciate the good in any manufactured object or commodity is constantly trained and developed so that our standards of taste both as individuals and as a Nation, may become better and better, as we know more about beauty.

The instinct for a beautiful home is present in all of us. If this instinct is guided and developed, a vast improvement in the homes of the people will result. "I have always felt" said the great English statesman, Disraeli, "that the best security for civilization is in the dwelling; and that upon properly appointed and becoming dwellings depends more than anything else the improvement of mankind."

A definite knowledge of the properties, the harmonies and the psychology of Color is nowhere more useful than in house furnishing. When ought one to use warm Colors, what will be the effect of cool Colors, where are advancing Colors desirable, what is the function of retreating Colors, what scheme should be used in a north bedroom or in a sunny dining room, or transversely, in a north dining room and in a sunny bedroom, what Colors will cause a room to look larger, what colors will stimulate, what colors will soothe, where should light values be used and what would be the effect of placing dark values in their places? All these questions can be settled through the intelligent use of Color in its relation to the furnishing of our houses.

Most people understand that curtains, rugs and the upholstery of furniture are important Color factors in house furnishing; but they do not always consider that the Color a room already has, before a single atom of "furnishing" is put in it, has a great deal to do with the ultimate effect. The Color tones of walls, floors, ceiling, woodwork or trim, lighting fixtures and window shades are quite as important elements in the creation of a harmonious room interior as are the "brought in" furnishings. Also, there is the question of location, as affecting the light from outside. North windows will bathe the room in cool, blue light, while the light that enters from south windows will be yellow or golden 
in tone. A knowledge of Color, not only of Color harmonies, but of other properties of Color, will help to solve the problem of properly furnishing the different rooms in our houses. Perhaps no other Color "law" will be a better foundation for us to build on than the law of backgrounds, for a room is really a background or a series of backgrounds created for the sole purpose of providing a setting for the various phases of family life.

The walls of a room are obviously a background against which must be seen the furniture, the pictures, the hangings and, last but not least, the people who live in the room. Therefore the walls must occupy a subordinate place,-not unimportant, but subordinate.

Dark backgrounds tend to make a room look smaller and light tones seem to make the walls expand. In Color tones, the walls should be related to the trim, the furniture and the hangings. Warm tans or grayed tints of orange are harmonious with chestnut or other brown tones of wood. Gray-green walls, in light value might be used with greenish tones of wood or paint. White walls seem to reflect light and are trying to the eyes, besides creating too violent contrasts between furniture, rugs, etc. Intense Colors should never be used upon walls, as they should always be more subdued than the shapes which are seen against them.

In choosing wall papers, a quiet tone or pattern showing little or no contrast in values is better than a paper showing a decided pattern; a light figure on a dark background, or the reverse. As walls are always to be flat, any treatment that disturbs or interferes with the effect of flatness is to be avoided. For this reason, realistic roses, trailing vines or vistas of landscapes on our walls are evidences of ignorance.

Floors are subject to the general laws that govern backgrounds. Floors are to be walked on and any decorative element that suggests the opposite of flatness is a transgression of the law. This settles the question of realistic garlands, roses, water lillies in pond, animals, etc., on rugs and carpets. Sharp contrasts of light and dark should also be avoided here, as these effects attract undue attention and appear to make the rug or carpet "come up" from the floor. In general Value the floor covering should be darker than the walls, and in Hue or Color tone it should be related to the walls and to the furnishing.

The ceiling should be distinctly lighter than the walls but it should 
be related to them in tone-for example, a cream or light buff ceiling should be used with tan or light gray orange walls. The presence of a common Color in floor, woodwork, walls and ceiling will bring them into harmonious relationship. For instance, in a scheme showing brownish tones in the floor, ivory white trim, light gray orange walls and a cream white ceiling, yellow is the common factor. A common factor such as this, is, in all color schemes, the great harmonizer. Such a setting is warm, bright and cheerful, and could be used with brown, green or orange rugs and hangings.

In a room with dark oak or chestnut trim, the walls should be related either by using gray tints of orange or its Complement, blue. With mahogany or reddish woodwork, either a warm gray or greenish tones are best. If one Color is taken as a tonal scheme, as in all monochromatic harmonies, the presence of a note of its Complement will relieve the otherwise too monotonous effect. For example, a "blue" room whose trim was painted gray blue, whose walls were light gray blue, and whose ceiling was a pale tint of gray blue was "saved" by the addition of curtains of unbleached muslin with bands of orange and blue cretonne, and a rug showing orange and blue in its patterns. In this room a bowl of nasturtiums or a jar of marigolds always seemed to be the crowning note of the decorative scheme.

In interior decorations, white and gray with all their subtle variations, as in cream, buff, ecru, light gray, orange, light gray green, light gray red, light gray blue, etc., are "safe and sane" tones to use in rooms where light effects are desired. Woodwork may be painted in these tones, wall papers may be found that show these Colors in patterns that do not vary greatly in values, rugs are obtainable that present these Colors in darker shades and ceilings may be calcimined in tones that faintly reflect this general scheme of walls and trim.

A principle of house furnishing that should be more generally observed is this: All wall spaces in a room should be treated as so many flat shapes or rectangles. The effect of a room with no furniture in it should be quiet and dignified. This effect we must aim to preserve when the furniture is placed. We may add, up to a certain point, lighting fixtures, hangings, and the various accessories necessary to the function of the room, but we must always maintain the "balance" of the room. Balance is destroyed by the bringing in of too many details, such as pictures, 
photographs, bric-a-brac, cushions, flags, draperies, etc. No Color harmony can compete with such an array of fussy detail.

Possibly the most difficult effect to secure in a room is personality, or "atmosphere." We do not look for this in hotel bedrooms or banquet halls, nor in railway stations. Yet all of these public places may be beautiful in color harmony and admirably fitted to their function. But in a home the personality of the individual, or the family should always be expressed. This will inevitably result when personal choice and personal "likes" are controlled by the observance of the laws of Color harmony.

Our houses always express us. If we are indifferent to the beauty of orderly arrangement and of Color harmony, they will show it. If we use what we have in the best way that is possible for those things to be used, our houses will bear witness to our love of order and to our feeling for and knowledge of beauty. 


\section{Chapter XIII}

\section{COLOR IN COMMERCIAL DESIGN}

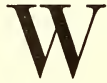

HEN we think of Color as a factor in commerce, the impression of a poster flashes into our minds. The wonderful part that posters are playing in these stirring times needs only to be mentioned in order to be conceded. We are living in what may be termed a "seeing" age. Books are no longer the chief means of distributing knowledge. Even the lecture platform and the pulpit employ the moving picture as a quick and sure means of conveying ideas. We still read the newspapers and we are sure to look at the cartoon of the day as expressing a definite idea of great interest in simple, direct terms. It is picture language, reduced to the lowest terms, and it is universally understood. The cartoon thus is classified with the poster, which, because of its simplicity, its directness and its color attraction, "hits the point" with swift precision.

Our government has learned to use posters in assembling armies, in inducing the people to save countless tons of food, in raising billions of money, in stirring all classes of men and women to high pledges of patriotism. It is the poster which has burned the beautiful symbol of the Red Cross into the consciousness of the peoples of all nations.

Recently the United States government undertook the task of distributing throughout Russia certain propaganda planned to influence the people of that country toward the ideals of Democracy. Extracts from great speeches and other writings which set forth the exalted aims of Freedom and Justice were gathered together. The best means of getting these thoughts and ideas into the minds of the Russian peoples was earnestly and thoroughly discussed. The futility of attempting to reach the masses through the newspapers of the country was immediately acknowledged. Russian peasants, as a rule, cannot read; hence the newspapers have little attraction for them. The plan of erecting immense billboards was finally hit upon. In hundreds of the cities and towns of Russia these great screens were constructed, and the messages, quota- 
tions and slogans which had been selected were translated into the Russian language, printed on twenty-four sheet posters and mounted upon the boards. Sometimes the text was used with appropriate decorations, and sometimes the screen presented only an arrangement of type, but always the element of Color was present. It is reported that these billboards created a decided sensation throughout Russia. Crowds of people gathered about them. Those who could read, told the less fortunate what the posters said. Thus was conveyed to all classes, learned and illiterate, the sympathy and friendship of the United States of America for all people who struggle for freedom. The poster with its dominating size, brilliant color and wide distribution, accomplishes quickly what the spoken, written or printed message would utterly fail to do.

In America, advertising by posters was probably started by the circus. We recall the pictures of gigantic size which were posted upon the billboards, barns and on any other available spaces on buildings, announcing that the circus with its marvels was coming to town. The pictures were as realistic as they could be made. They showed elephants from the jungle, camels from the desert, polar bears on icebergs, buffaloes from the plains or a crouching tiger ready to spring upon its prey. They were crude in color, poor in drawing, and showed no sense of composition or arrangement, yet they fulfilled the first and most important function of the poster-they attracted attention, exciting interest and made people anxious to go to the circus!

It was not long before manufacturers and merchants adopted the pictorial method of bringing their wares to the attention of the public. Soon "Bixby's Best Blacking" appeared in posters that showed a pair of boots, in whose shining surfaces were reflected the complacent countenance of the bootblack. As a result of these pictures, no doubt, vast quantities of "Bixby's Best" were sold.

The drawing, the composition and the coloring of these early posters were very crude. People of refined taste objected strongly to the display of so low a grade of Art upon the streets and along the avenues of commerce. Gradually, in response to a demand for better things, improvement was noticeable in posters. Designers discovered that simple, flat shapes and a few colors well a1 ranged could be seen farther than shapes that were treated to represent details of surface in realistic colors, E 
hence the fact was established that the decorative treatment of shapes and colors was better than the pictorial or realistic treatment for the advertiser's purpose.

The billboards of today, which we acknowledge are the great public news carriers, are rapidly becoming great public Art galleries as well, for some of the most dignified and serious Art work of our country, as well as of other countries, is now expressed through posters. Great progress has also been made in the invention of non-fading inks of fine color quality and in the manufacture of a certain poster paper which sheds water and with a surface that is adapted to the printing of large masses of inks. The people are much interested in Poster Art, and when the people appreciate and encourage the work of good designers, the products are sure to be of high merit.

The importance of Color as a factor in Commercial Design is obvious. Can we imagine a poster without Color? Can we question the importance of an understanding, on the part of the poster designer, of the various properties and attributes of Color? A man in business may scoff at the suggestion that a knowledge of the laws of Color harmony is necessary for the full enjoyment of his home, or he may ridicule the idea that his necktie is a criterion by which his esthetic station in life may be designated, but he will listen with respectful attention when he is told that certain colors, scientifically considered, have more power to attract than other colors. He can understand that this kind of Color knowledge will bring in returns, in terms of dollars and cents. If a poster which advertises the wares that he offers for sale attracts more attention than the poster used by a competitor, he is convinced that Art, or at least that phase of Art which affects posters, has practical value. He sees that Art may be made to serve a commercial purpose and for that reason he is willing to invest in it.

The first function of a poster is fulfilled when people are compelled to look at it. If a poster fails to induce the eye to rest upon it, it "might as well not be, as be." Through the flash of Color, the eye is first attracted. If the fleeting glance registers a thrill, the eye looks again, notes the shape of the Color and pauses to read the short, crisp text. So, like the click that registers the taking of the kodak picture, the idea goes home, and the work of the poster is accomplished. 
The poster designer must understand not only the principles of color harmony, but he must know the psychology of Color as well. $\mathrm{He}$ must appreciate the fact that a poster which sets forth the attractions of a summer resort in Maine, should not show the same Color scheme as a poster which advertises a winter cruise in the Mediterranean. He must know which colors are "advancing" and which are "retreating" in their effect upon the eye and mind. He must understand that dignity and seriousness, lightness and joy, tragedy and sorrow may be suggested by Colors, as well as by words. He must realize that a poster must in the last analysis be beautiful as well as forceful, in order to perform its most effective work.

Poster effects are used in many places. Not only on billboards do we observe a flat, simple treatment of strong pure Color. We see it in other forms, common in commercial usage-in book covers, post cards, poster stamps, box covers, labels, display cards, and in magazine covers and advertisements. In all these forms, the best is always that which makes the strongest appeal, in a beautiful harmony. We must not forget that harmony is possible through the use of pure colors. It is a difficult problem to bring pure, intense colors into harmonious relationship, but it is by no means impossible of solution.

A stranger in a western town paused before the window of a shoe store, not because she was interested in shoes at that time, but because she saw in that window as beautiful an arrangement of Color harmonies as is presented in many a picture. There was nothing in that window but shoes and a paper background. The lady was astonished that so prosaic an article could be the means of expressing so interesting a Color scheme. The fact was evident that an intelligent mind had thought out the scheme and had arranged the display. People paused to look at it because it was different from other shoe displays and they went away thinking that the window was interesting and beautiful. Perhaps they did not know why. It would have given them an added interest if they had understood. The background and floor of the window were covered with violet and white striped paper. A number of packing boxes had been utilized as stands at different levels for the shoes to rest upon, and these also were covered with violet and white paper. Against this background were arranged dozens of pairs of shoes, every size and kind being repre- 
sented, except that they were restricted as to Color, for they were all either white, black or tan. The three colors were so distributed that a balanced composition of black, white and yellow (tan) against a violet and white background was created. Thus the law of Complementary harmony was observed, with the addition of the neutrals black and white, which supplied the "snap" and "punch" that are indispensable in any advertising arrangement. The stranger entered the store to congratulate the owner upon the success of his window and being in the store she remembered that she needed a pair of rubbers. It is not likely that her purchase was the only one that resulted from the attractive arrangement in the window. The shoe dealer's primary object was not to present a Color harmony for the satisfaction of the esthetic eye, but to sell shoes. He used the striking Color harmony only as a means of compelling some passer-by to look, and looking, the possible buyer registered on his mind a favorable impression of this dealer's shoes.

In Commercial Design the law of backgrounds must be observed as strictly as in the furnishing of a room. The background must be always less intense in color than the shapes that are placed against it. The reason for this is plain. Attention is to be called not to the background, but to the shapes of objects and to the words that are printed on the background. If, on a background of intense orange were printed shapes in blue, brown and gray, the background would assert itself more strongly than the shapes. If the order were reversed and the blue, orange and brown shapes were seen against a gray background, the shapes would "hold their own" without conflict. If we understand then, that "retreating" Colors and grayed tones are best for backgrounds, and that "advancing" Colors are to be selected for those shapes to which we desire to call attention, we shall be sure of a principle that it will be safe to follow.

Strong contrasts of dark and light, even in a Monochromatic scheme will always attract the eye. Light shapes against dark, or dark against light, will strengthen a poster's appeal. This is the very effect we wish to avoid in a rug, however. A too light border or shape will overbalance a large area of tones that are subtle in their relationship. When we know the law we can obey it intelligently, and find in its observance the greatest satisfaction. 
There is another quality of Color most important to the commercial designer, and that is the quality which we call Luminosity. A luminous Color reflects and even seems to emit light. Certain luminous Colors strongly suggest light. Of all Colors in the Chromatic Circle, yellow is the most nearly like actual light. It is the carrying, penetrating color and when mixed with red, which gives it depth and strength, the resultant Color, orange, can be seen at a greater distance than any other color. This is the reason that the so-called red lights (which are really red-orange) are used as railway signals. Light shining through a yellow or orange shade will pierce farther into the darkness than light which shines through clear glass, or through a green or blue glass. A green lamp shade is restful to the reader because it reduces the intensity of white light, but it does not light the room so well. Again, a yellow, orange or red shade placed around artificial light sends a warm, becoming glow over the people who come under the influence, while the unbecomingness of the greenish light which proceeds from green shades is well known.

When we add yellow the most luminous color, to red, the most warm and vital color, we produce orange, which is perhaps the most attractive, far reaching and compelling Color known. It does not excite or stimulate to the point of irritation as red does, but it has just enough of the red quality to attract and hold the attention. For this reason, orange in some intensity or value is used on nearly every poster that is made, for those shapes where the interest is intended to be centered.

All Colors possess in varying degrees the quality of luminosity. We may even speak of a luminous blue, although blue is very low in the scale of luminosity. The order of colors in their degree of Luminosity may be stated as follows: yellow, orange, green, red, blue and violet.

All that we can learn about Color, its properties, its harmonies its psychology, its mission as a universal language to express and to convey definite ideas and impressions can be applied to every activity of life. Thus in our effort to educate the people, so that they may be fitted to the times in which they live, contributing their part to civilization, and enjoying the fullness, usefulness and beauty of a well rounded development, instruction in the Science and Art of Color should play an important part. 


\section{“QUARTO ART BOOKS”}

Uniform with this volume

\section{LETTERING,}

Postpaid

By Thomas Wood Stevens......... \$2.25

WITH PEN AND INK,

By James Hall.............. 2.25

PENCIL SKETCHING,

By George W. Koch............ 2.25

MONOGRAMS AND CIPHERS,

By A. A. Turbayne............ 2.25

TWELVE GREAT PAINTINGS,

By Henry Turner Bailey........... 2.25

ART SIMPLIFIED,

By Pedro J. Lemos and John T. Lemos. 2.50 (Loose Leaf)

PRINCIPLES OF ADVERTISING

ARRANGEMENT,

By Frank Alvah Parsons (Tall Quarto) 2.25

Sent Postpaid on receipt of price

THE PRANG COMPANY, New York, Chicago, Boston 



